\title{
Resource Utilization of Agricultural Residues: One- Step Preparation of Biochar Derived From Pennisetum Giganteum For Efficiently Removing Chromium From Water In A Wide pH Range
}

\author{
Yao Chen \\ Kunming University of Science and Technology \\ Ping Ning C \\ kunming university \\ Rongrong Miao \\ Kunming University of Science and Technology \\ Liang He ( $\nabla$ heliang@kust.edu.cn ) \\ Kunming University of Science and Technology \\ Qingqing Guan \\ Kunming University of Science and Technology
}

\section{Research Article}

Keywords: Agricultural residues, $\mathrm{H} 3 \mathrm{PO}$ 4-treated biochar, $\mathrm{pH}$ range, $\mathrm{Cr}(\mathrm{VI})$, Selective adsorption

Posted Date: June 10th, 2021

DOI: https://doi.org/10.21203/rs.3.rs-555967/v1

License: (c) (i) This work is licensed under a Creative Commons Attribution 4.0 International License.

Read Full License

Version of Record: A version of this preprint was published at Environmental Science and Pollution Research on July 23rd, 2021. See the published version at https://doi.org/10.1007/s11356-021-15388-y. 
Resource utilization of agricultural residues: One-step preparation of biochar derived from Pennisetum giganteum for efficiently

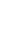
removing chromium from water in a wide $\mathrm{pH}$ range

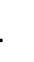
Yao Chen ${ }^{\mathrm{a}, \mathrm{c}}$, Ping Ning $\mathrm{c}^{*}$ Rongrong Miao ${ }^{\mathrm{a}, \mathrm{c}}$, Liang He ${ }^{\mathrm{b} *}$, Qingqing Guan ${ }^{\mathrm{a} *}$, ${ }^{a}$ Faculty of Civil Engineering and Mechanics, Kunming University of Science and

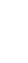
Technology, Kunming, China ${ }^{b}$ Faculty of Chemical Engineering, Kunming University of Science and Technology,

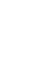
Kunming, Yunnan 650500, China

'Faculty of Environmental Science and Engineering, Kunming University of Science and Technology, Kunming, China

11 Abstract: Biochars derived from agricultural residues, Pennisetum giganteum, were

12 prepared by a one-step activation method after impregnated with $\mathrm{H}_{3} \mathrm{PO}_{4}$. The effects of 13 activation temperature and $\mathrm{H}_{3} \mathrm{PO}_{4}$ impregnation method on the structure and 14 performance of biochar were investigated. Characterizations such as XPS, FTIR, and

$15 \mathrm{~N}_{2}$ adsorption-desorption curves showed that the P-containing biochar prepared by 16 one-step method had a large specific surface area, large pores, and abundant surface

17 functional groups. And, C-P, O-P, C-O, and other groups participated in the adsorption 18 and removal of $\mathrm{Cr}(\mathrm{VI})$. Moreover, the target adsorbent has a good effect on $\mathrm{Cr}$ removal 19 in a wide range of $\mathrm{pH}$ (the removal rate was more than $55.92 \%$, at $\mathrm{pH} \leqslant 9$ ).

20 Interestingly, the changing trend of $\mathrm{pH}$ value in the reaction process under different

21 initial $\mathrm{pH}$ values proved that the adsorbent itself could regulate the $\mathrm{pH}$ of the external

*Corresponding Author: Tel: +8615687654177

Email ID: heliangkmust@163.com (Liang HE); 15545488@qq.com (Qingqing Guan); ningping1958@163.com 
22 solution by providing acid groups, thus keeping the adsorption equilibrium solution in

23 a narrow $\mathrm{pH}$ range. In addition, the target adsorbent had excellently selective

24 adsorption capacity and good removal capacity $(\geqslant 77.4 \%)$ after five times of reuse.

25 This work should permit for providing a convenient utilization of Pennisetum

26 giganteum agricultural residues and confirmed that the biochar treated with $\mathrm{H}_{3} \mathrm{PO}_{4}$ can

27 remove chromium in a wider $\mathrm{pH}$ range through self-regulation.

28 Keywords: Agricultural residues; $\mathrm{H}_{3} \mathrm{PO}_{4}$-treated biochar; $\mathrm{pH}$ range; $\mathrm{Cr}(\mathrm{VI})$; Selective

29 adsorption

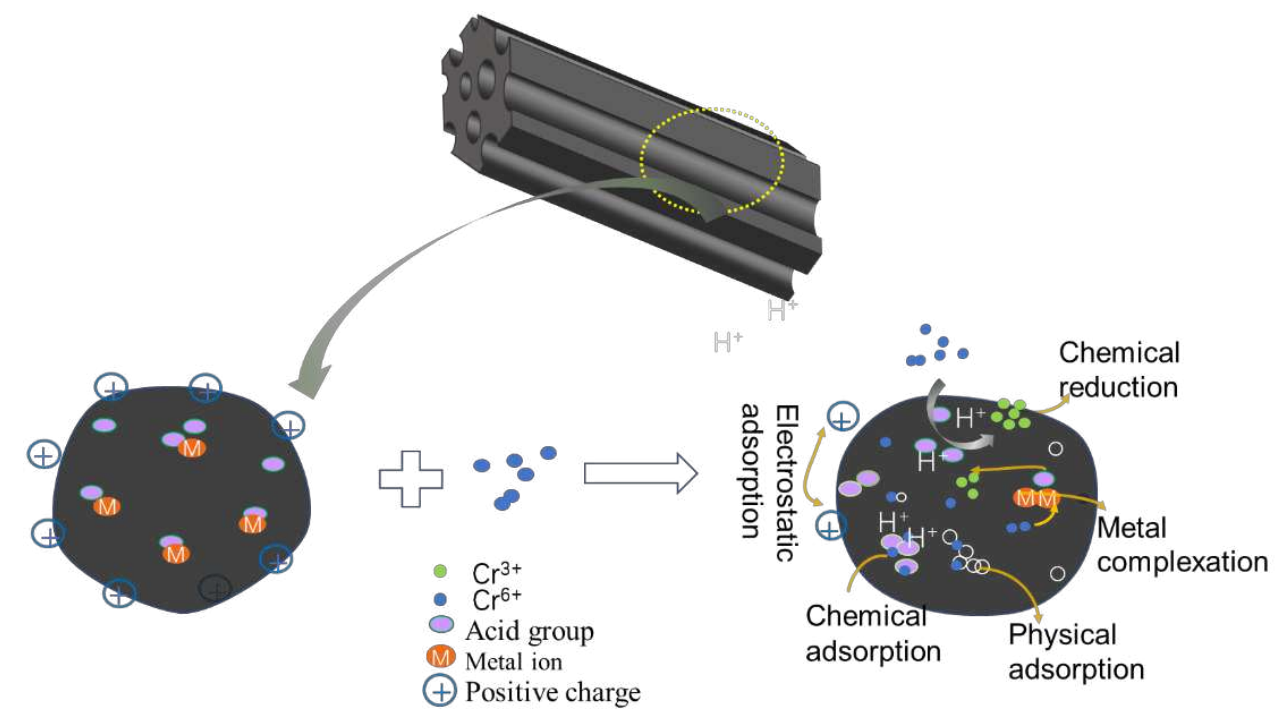

\section{1. Introduction}

32 Chromium $(\mathrm{Cr})$ is a toxic heavy metal that constitutes a seriously threat to human

33 health (Santiago et al. 2010). Chromium is derived from a wide range of sources,

34 including electroplating, leather, printing and dyeing, metallurgy among others (Xin et al.

35 2018). In an aquatic environment, chromium primarily exists in two stable oxidation

36 states: $\mathrm{Cr}$ (III) and $\mathrm{Cr}$ (VI). Cr (VI) has high mobility in the aquatic system and is about

37500 times more toxic than $\mathrm{Cr}$ (III) (Jiang et al. 2015). Cr (VI) is carcinogenic (causing

38 lung cancer), causes dermatitis, renal circulation, and other serious diseases. The US

39 EPA regulated the $\mathrm{Cr}(\mathrm{VI})$ concentration standards as $<0.1 \mathrm{mg} \mathrm{L}-1$ for natural waters and 

$<0.05 \mathrm{mg} \mathrm{L}-1$ of drinking water (Onchoke \& Sasu 2016). Therefore, the treatment of Cr

41 (VI) pollutants was of importance to public health and environmental protection.Several

42 methods, including chemical precipitation, electrocoagulation, electrochemical

43 treatment, reverse osmosis, membrane filtration or ion exchange and adsorption, have

44 been employed to remove Cr (VI) from aqueous solutions(Ankur \& Chandrajit 2016;

45 Ramavandi et al. 2014; Zhao et al. 2017). Among these methods, adsorption technique

46 was considered as an efficient and attractive method owing to its effectiveness,

47 simplicity, and cheapness (Jiang et al. 2018). At present, a variety of adsorbents(such as

48 biochar, polymer, gel, natural, and waste) were reported to be used as clay minerals for

49 the treatment of polluting wastewater (Sophia \& Lima 2018). Biochar, is a relatively

50 new adsorbent, that has attracted increasing attention on account of its rich and

51 renewable properties in raw materials and the characteristics of "treating waste with

52 waste" (Singh et al. 2019; Tong et al. 2019). Because of its rich surface functional groups,

53 large porosity and ability to reduce reduce carbon emissions, biochar be used as a cheap

54 carbon material adsorbent and can meet the requirements of low-cost adsorbent to

55 remove heavy metals, and can be used to treat industrial wastewater. (Chao et al. 2015;

56 Kong et al. 2014). The removal of metal ion by biochar is the result of a variety of

57 mechanisms, including precipitation, complexation, ion exchange, electrostatic

58 adsorption and physical adsorption (Dong et al. 2011a). Specific ligands and functional

59 groups, such as $-\mathrm{OH}$ and $-\mathrm{COOH}$ on the surface of biochar can form complexes or

60 precipitates with heavy metals (Mahdavi et al. 2013), which belonged to chemical

61 adsorption. However, physical adsorption mainly depended on the surface properties of

62 biochar, such as specific surface area and pore structure (Sigmund et al. 2017). Most

63 studies showed that it was impossible to become an important mechanism for heavy 
metal adsorption. The surface charge of biochar adsorbs metal ions with an opposite

65 charge through electrostatic interaction, which is one of the main mechanisms of

66 removing heavy metal ions by biochar. For example, biochar prepared at high

67 temperature $\left(>400{ }^{\circ} \mathrm{C}\right)$ is easy to form a graphene structure, which further improves the

68 electrostatic adsorption capacity of biochar and heavy metals (Wang 2018).

69 Generally, the adsorption mechanism of metal ions by biochar prepared by different 70 activators is quite different. T The common activators are $\mathrm{ZnCl}_{2}, \mathrm{KOH}, \mathrm{Na}_{2} \mathrm{CO}_{3}, \mathrm{H}_{3} \mathrm{PO}_{4}$,

71 etc. Yang et al. (Li et al. 2020). Researchers (Yu et al. 2020) used $\mathrm{FeCl}_{3}$ and $\mathrm{ZnCl}_{2}$

72 modified corn straw to remove $\mathrm{Cr}(\mathrm{VI})$, and its adsorption capacity could reach 138.89

$73 \mathrm{mg} \mathrm{g}-1$, but the solution environment had to be adjusted to $\mathrm{pH}=2$. The addition of

74 polyethyleneimine and phosphorus increased the number of active centers of the biochar

75 from the oil tea shell, and the adsorption capacity reached $355 \mathrm{mg} \mathrm{g}-1$ (Chen et al. 2018).

76 For the materials reported in the literature, the $\mathrm{pH}$ value of the solution usually should be

77 adjusted to acidic conditions (usually $\mathrm{pH}<3$ ), which was confined within a narrow range

78 (Sigmund et al. 2017; Xin et al. 2018). Therefore, the development of new biochar

79 adsorbents with low cost and large $\mathrm{pH}$ range is still the sustainable goal of environmental

80 remediation. However, in the past, studies focused on how to improve the adsorption

81 capacity of the adsorbent (Ahmadi et al. 2016), and few researchers paid attention to

82 how to modify the adsorbent to make the adsorbent have better chromium removal effect

83 in a wide range of $\mathrm{pH}$.

84 Herein, a new type of $\mathrm{H}_{3} \mathrm{PO}_{4}$-porous carbon was prepared by direct pyrolysis

85 Pennisetum giganteum, w which was earlier impregnated with phosphoric acid..

86 Homogeneous carbonized biomass materials were prepared by one-step carbonization

87 activation at a lower temperature. The adsorption isotherm and kinetic model were 
analyzed and the stability of P-pg BC was tested. The results showed that phosphoric

89 acid activated biochar can self-regulate the $\mathrm{pH}$ of the system. By providing protons, the

$90 \mathrm{pH}$ of the initial solution was finally maintained in a narrow $\mathrm{pH}$ range. The purpose of

91 this study is to synthesize biochar with sufficient surface acidity, which can remove

92 chromium in a wide range of $\mathrm{pH}$, to reveal the relationship between surface groups and

93 adsorption properties of biochar. remove chromium in a wide range of $\mathrm{pH}$, to reveal the

94 relationship between surface groups and adsorption properties of biochar.

\section{2. Material and method}

962.1 Materials and Reagents

Pennisetum giganteum was kindly provided by Kunming Hengfa Technology Co.,

98 Ltd, Yunnan, China. Sodium hydroxide $(\mathrm{NaOH})$, phosphoric acid ( $\geq 85.0 \%$ ), acetone

$99(\geq 99.0 \%)$, furfural $(\geq 99.5 \%)$, sulfuric acid ( $\geq 98 \%)$, potassium dichromate $(\geq 99.9 \%)$,

100 and the other AR reagents were purchased from Shanghai McLean Biochemical

101 Technology Co., Ltd. Deionized water was used to prepare all solutions and all the

102 experimental steps. All chemicals used in this study were of commercially available 103 analytical grade and used without further purification.

104 2.2 Preparation of activated carbon from Pennisetum giganteum (P-pgBC)

105 First of all, the Pennisetum giganteum stem should be washed and dried overnight

106 in the oven. The dried Pennisetum giganteum was crushed with a grinder, screened 107 through a 40-60 mesh sieve, and packed in plastic bags for standby (named as raw 108 material). And then, there were two kinds of activation methods: one was that the raw 109 materials were pre-carbonized, and then the pre-carbonized carbon was mixed with a 110 certain proportion of phosphoric acid $(1: 1,1: 2,1: 3)$, and then activated directly in the $\mathrm{N}_{2}$ 111 atmosphere at target temperature (labeled as $\mathrm{Yp}-\mathrm{pgBC}-\mathrm{X}{ }^{\circ} \mathrm{C}$ ), the other was mix the raw 
112 material with phosphoric acid in a certain proportion $(1: 1,1: 3)$, immersed it in an oven at

$11360{ }^{\circ} \mathrm{C}$ for $24 \mathrm{~h}$, and then activated it in $\mathrm{N}_{2}$ atmosphere at target temperature (labeled as

$\left.114 \mathrm{Zp}-p g \mathrm{BC}-\mathrm{X}{ }^{\circ} \mathrm{C}\right)$. Among them, the condition of pre-carbonization refered to that 115 carbonization in nitrogen atomosphere at $400{ }^{\circ} \mathrm{C}$ for $2 \mathrm{~h}$ in a tube furnace.

116 he activation temperature was between $300{ }^{\circ} \mathrm{C}$ and $500{ }^{\circ} \mathrm{C}$, the rate was $5 \mathrm{~K} / \mathrm{min}$, and the

117 time was $1 \mathrm{~h}$. The materials prepared by the two methods were washed to neutral with 118 deionized water and then dried in the oven overnight. Grind the dried materials and put

119 them into plastic bags for standby. At this point, the adsorbent was ready.

$120 \quad 2.3$ Characterization

121 S $\mathrm{S}_{\mathrm{BET}}$ and pore size of $\mathrm{Z}_{\mathrm{P}-p g B C-400}{ }^{\circ} \mathrm{C}$ were completed by

122 Brunauer-Emmett-Teller and Barrett-Joiner-Halenda method. The phase structure of

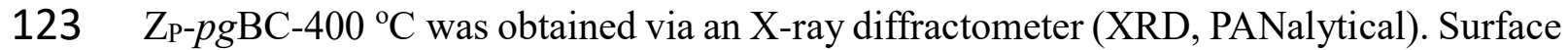

124 element composition and element valence analysis also were examined by X-ray

125 photoelectron spectroscopy (XPS, Thermo fisher Scientific K-Alpha ${ }^{+}$). Fourier

126 transforms infrared (FTIR) spectra were recorded on an FTIR Spectrophotometer in the

127 range of $4000-500 \mathrm{~cm}^{-1}$ using $\mathrm{KBr}$ pellet. SEM and EDS were performed by field

128 emission scanning electron microscope (Sigma model, Zeiss, Germany).

129 2.4 Batch Cr(VI) adsorption experiments

130 The typical adsorption process is as follows: $50 \mathrm{~mL} \mathrm{Cr}(\mathrm{VI})$ solution $(10-100 \mathrm{mg} / \mathrm{L})$

131 and required weight of adsorbent $(0.5-2.0 \mathrm{~g} / \mathrm{L})$ were added in a $150 \mathrm{ml}$ conical flask for

132 a batch experiment. Also, the effects of $\mathrm{pH}(1-9)$, contact time (0-24 h), and temperature

$133\left(25,40\right.$, and $\left.55^{\circ} \mathrm{C}\right)$ on $\mathrm{Cr}$ (VI) adsorption efficiency were also studied. And all speeds of

134 the reciprocating shaker were set to $160 \mathrm{rpm}$. The $\mathrm{pH}$ of the solution was adjusted with

$1350.1 \mathrm{M} \mathrm{NaOH}$ and $0.1 \mathrm{M} \mathrm{HCl}$. After $24 \mathrm{~h}$, The concentration of remaining $\mathrm{Cr}(\mathrm{VI})$ anions 
in the adsorption medium was determined at $540 \mathrm{~nm}$ using a double beam UVeVIS

137 spectrophotometer after complexation with 1,5 diphenylcarbazide. To ensure the

138 accuracy, reliability, and reproducibility of the data, all the batch experiments were 139 carried out in triplicate for statistical purposes and the adsorption capacities were 140 calculated by the following equation:

$141 \quad$ Adsorption efficiency \% :

$$
\eta=\frac{C_{0}-C}{C_{0}} \times 100 \%
$$

143 Adsorption capacity:

$$
\mathrm{q}=\frac{\left(C_{0}-C\right)}{m} \times V
$$

Where $\mathrm{C}_{0}$ and $\mathrm{C}(\mathrm{mg} / \mathrm{L})$ are the initial and equilibrium concentrations of $\mathrm{Cr}(\mathrm{VI}), \mathrm{m}$

146 is the mass of absorbent $(\mathrm{g})$, and $\mathrm{V}(\mathrm{L})$ is the volume of solution.

\section{3. Results and Discussion}

\section{$148 \quad 3.1$ Optimization of Activation Conditions}

Before the formal experiment, a large number of pre experiments were carried out, and the best adsorption materials were selected. Firstly, the carbon materials prepared by

$151 \mathrm{KOH}$ two-step activation method reported by our research group were tested. It was

152 found that it took long time for the adsorption to reach equilibrium, and the high removal

153 efficiency could be only under acidic conditions(文献). Therefore, five kinds of carbon 154 materials were prepared by using phosphoric acid as an activator and their removal 155 effects were tested. And, the concentration of $\mathrm{Cr}(\mathrm{VI})$ was $50 \mathrm{mg} / \mathrm{L}$, the reaction 156 temperature was $25^{\circ} \mathrm{C}$, and the amount of adsorbent was $0.1 \mathrm{~g}$. The chromium solution 157 used was the natural $\mathrm{pH}$ value.

According to Table S1, the biochar prepared via one-step method has a good

159 removal effect on $\mathrm{Cr}(\mathrm{VI})$, and the optimal mass ratio of carbon to phosphorus is 1:3. 160 Next, the effects of activation temperature on the surface area, pore volume, and 
161 removal efficiency of porous carbon materials were studied. The results of chromium

162 adsorption experiments of the adsorbents prepared at three different activation

163 temperatures at different $\mathrm{pH}$ were tested (Fig.1). Very clearly, biochar prepared at 400

$164{ }^{\circ} \mathrm{C}$ had the best effect, and the removal rate was more than $98 \%$ at the $\mathrm{pH}$ of natural

165 chromium solution $(\mathrm{pH}=5.25)$, which was much milder than the acidic conditions

166 reported in the literature. As shown in Table S2, Zp-pgBC-400 ${ }^{\circ} \mathrm{C}$ had the best removal

167 effect, and the adsorption capacity reached $30.52 \mathrm{mg} / \mathrm{g}$. And, the $\mathrm{N}_{2}$

168 adsorption-desorption behavior of the $\mathrm{Zp}-\mathrm{pgBC}-400{ }^{\circ} \mathrm{C}$ has been displayed in Fig. 2,

169 which concluded that it had an excellent specific surface area $\left(749.9 \mathrm{~m}^{2} / \mathrm{g}\right)$ with a pore

170 diameter of $\sim 4.6 \mathrm{~nm}$. It can be seen from Fig. 2, it had an obvious hysteresis loop,

171 which belonged to the type IV adsorption curve and was an obvious adsorption curve

172 of mesoporous adsorption materials. The nitrogen adsorption and desorption curves of

173 materials calcined at $300{ }^{\circ} \mathrm{C}$ and $500{ }^{\circ} \mathrm{C}$ are shown in Fig. S1. The results showed that

174 the specific surface area of the material calcined at $300{ }^{\circ} \mathrm{C}$ and $500{ }^{\circ} \mathrm{C}$ are $81.9 \mathrm{~m} / \mathrm{g}$ and

$1751032.02 \mathrm{~m}^{2} / \mathrm{g}$, and the pore sizes are $10.41 \mathrm{~nm}$ and $4.84 \mathrm{~nm}$, respectively. The material

176 calcined at $300{ }^{\circ} \mathrm{C}$ had the smallest specific surface area, least adsorption sites, which

177 explained the poorest performance of $\mathrm{Zp}-p g B C-300{ }^{\circ} \mathrm{C}$. Compared to $400{ }^{\circ} \mathrm{C}$, the

178 specific surface area increased at $500{ }^{\circ} \mathrm{C}$, but the adsorption performance decreased.

179 The decrease in the adsorption properties may be due to the decreases in the number of

180 oxygen-containing groups at high temperatures (Calisto et al. 2014). The BET data

181 were in good agreement with the experimental results (Fig. 1). 


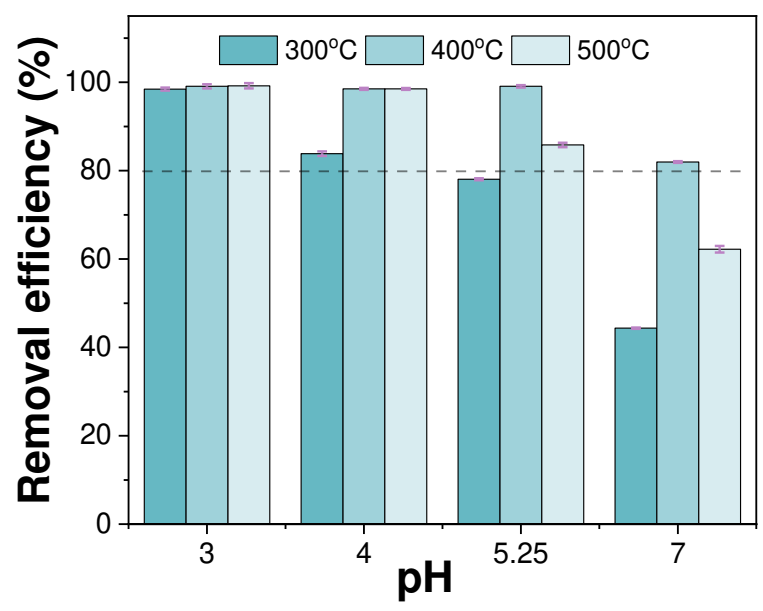

182

Fig. 1. $\mathrm{Cr}(\mathrm{VI})$ removal efficiency at three activation temperatures. (Initial concentrations $=50 \mathrm{mg} / \mathrm{L}$, Solution $\mathrm{pH} 5.25$, and $\left.\mathrm{T}=25^{\circ} \mathrm{C}\right)$.

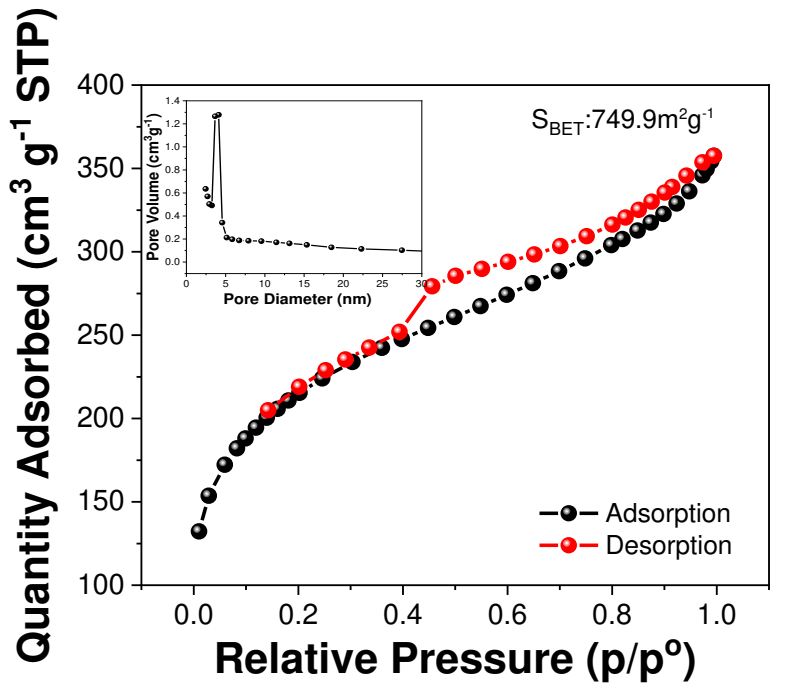

Fig. 2. $\mathrm{N}_{2}$ adsorption/desorption isotherms and pore size distribution curve of $\mathrm{Z}_{\mathrm{p}-p g B C-400}{ }^{\circ} \mathrm{C}$.

3.2 $\mathrm{Cr}(\mathrm{VI})$ adsorption studies

3.2.1 Effect of adsorbent dosage and $\mathrm{pH}$

Adsorbent dosage and the $\mathrm{pH}$ of $\mathrm{Cr}(\mathrm{VI})$ solution are of particular importance in

191 analyzing the adsorption procedure and exploring the adsorption ability (Suganya \&

192 Kumar 2018; Zhang et al. 2017). In Fig. 3(a), removal of $\mathrm{Cr}(\mathrm{VI})$ was studied at $25^{\circ} \mathrm{C}$

193 and $160 \mathrm{rpm}$ for $24 \mathrm{~h}$ in the initial concentration of $50 \mathrm{mg} / \mathrm{L}$, with different dosage of 
adsorbents. With the increase of adsorbent concentration in solution, the removal efficiency of $\mathrm{Cr}$ first increased rapidly, then reached a good removal efficiency (> 97.01\%) at the adding $=1.5 \mathrm{~g} / \mathrm{L}$. Then with the increase of the amount of adsorbent, the 197 adsorption capacity first tended to be stable and then decreased. Therefore, $1.5 \mathrm{~g} / \mathrm{L}$ adsorbent can not only achieve a high removal rate but also achieve adsorption saturation.

The adsorption performance of biomass-based adsorbents may be closely related

201 to the $\mathrm{pH}$ value of the solution, which affects both the existence of chromium and the 202 charge properties of the adsorbent (Dong et al. 2011b; Yin et al. 2019; Zhang \& Zheng 203 2015). As shown in Fig. 3(b), Cr(VI) had the maximum removal rate (> 97.01\%) and

204 higher adsorption capacity $(31.4 \mathrm{mg} / \mathrm{g})$ at $\mathrm{pH} \leq 5.25$. When the $\mathrm{pH}$ value is higher than 2057 , the removal rate and adsorption capacity decrease rapidly. At $\mathrm{pH}=7$, the removal 206 efficiency of $\mathrm{Cr}(\mathrm{VI})$ was $78.2 \%$, and only $55.92 \%$ when it increased to 9 . With the

207 increase of $\mathrm{pH}$ value, the removal rate was decreasing, which was because the $\mathrm{pH}$ 208 value of the solution greatly affected the existence form of chromium species (Zhang 209 \& Zheng 2015).

210 Interestingly, the removal effect of chromium was not bad at a high $\mathrm{pH}$ value.

211 Therefore, Fig. 3(c) measures the real-time change of $\mathrm{pH}$ value during the adsorption

212 process. It can be observed that when the initial $\mathrm{pH}$ was 7.04 and 8.98 , the $\mathrm{pH}$ of the

213 solution decreased rapidly within 10 minutes after the adsorbent was added. After 200

214 minutes, the $\mathrm{pH}$ of all solutions hardly changed and reached equilibrium. The

215 mechanism analysis showed that the rich oxygen-containing functional groups on the

216 surface of biochar could keep the $\mathrm{pH}$ value of the solution at $3.1-5.41$, when the initial

$217 \mathrm{pH}$ value was $3.04-8.98$. The species distribution of chromium species at different $\mathrm{pH}$ 
218 values is shown in Fig. 3d. Combined with Fig. 3c, it is found that the main chromium

219 species in the solution is $\mathrm{HCrO}_{4}^{-}$, in which the removal mechanism can be explained by 220 Eq. 3. This was a good explanation of why $\mathrm{Z}_{\mathrm{p}}-p g \mathrm{BC}-400{ }^{\circ} \mathrm{C}$ still had a good removal 221 effect under alkaline conditions (See FTIR and XPS for more details).

$$
\mathrm{HCrO}_{4}^{-}+7 \mathrm{H}^{+}+3 \mathrm{e}_{-}^{-} \longrightarrow \mathrm{Cr}_{3}{ }^{+}+4 \mathrm{H}_{2} \mathrm{O}
$$

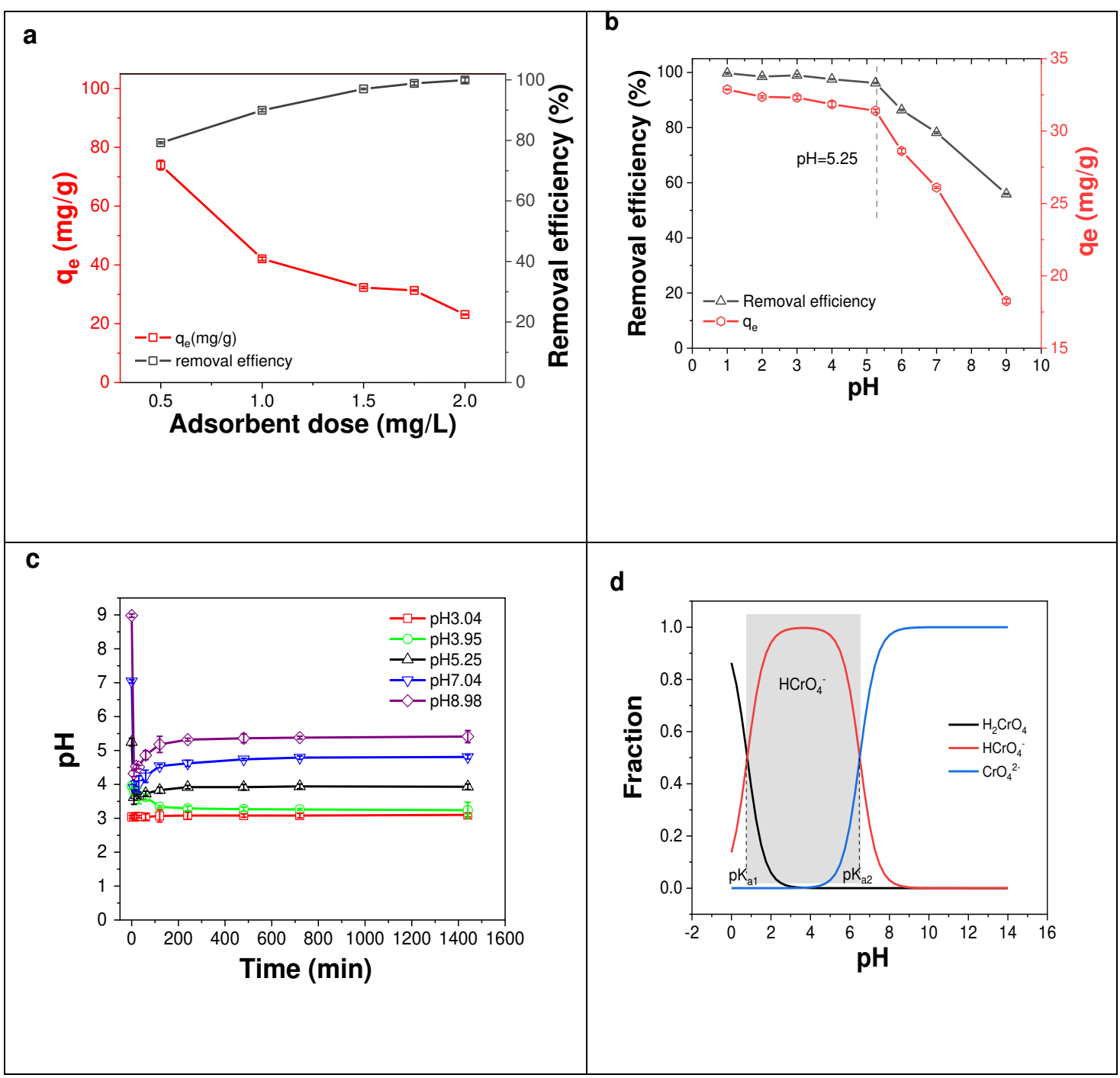

224 Fig. 3. Effect of dosage (a) and solution $\mathrm{pH}$ (b) on $\mathrm{Cr}(\mathrm{VI})$ removal ; (c)pH changing trend during reaction under various initial $\mathrm{pH}$ (5.25 was the intrinsic $\mathrm{pH}$ of the solution). $\mathrm{T}=298 \mathrm{~K}, \mathrm{C}_{0}(\mathrm{VI})=50 \mathrm{mg} / \mathrm{g}, \mathrm{rpm}=160$ 
Various factors affecting $\mathrm{Cr}(\mathrm{VI})$ adsorption, and the contact time is one of the

229

230

231

232

233

235

236

237

238

239

240

241

242

$243\left(\mathrm{R}^{2}=0.946\right)$, which indicated that the rate-limiting step was a chemisorption process

244 (Liang et al. 2020). Besides, the adsorption values calculated by the pseudo-second

245

246 (32.458 mg/g). In Fig. 4(b), the results exhibited that the adsorption efficiency can be

247 well fitted with the Elovich model with $\mathrm{R}^{2}$ of $=0.9956$, suggesting the existence of the

248 chemical effect, and $\mathrm{Cr}(\mathrm{VI})$ adsorption was on the surface of heterogeneous solid

249 adsorption (Guan et al. 2020). In Fig. 4 (c), $\mathrm{R}^{2}$ of the three-stage intraparticle diffusion

250 model were greater than 0.99 , indicating that the internal diffusion played a certain role

251 in the actual adsorption process, but the lines have not been passed through the origin, 
252 exhibiting that intragranular diffusion is not a speed limiting step.

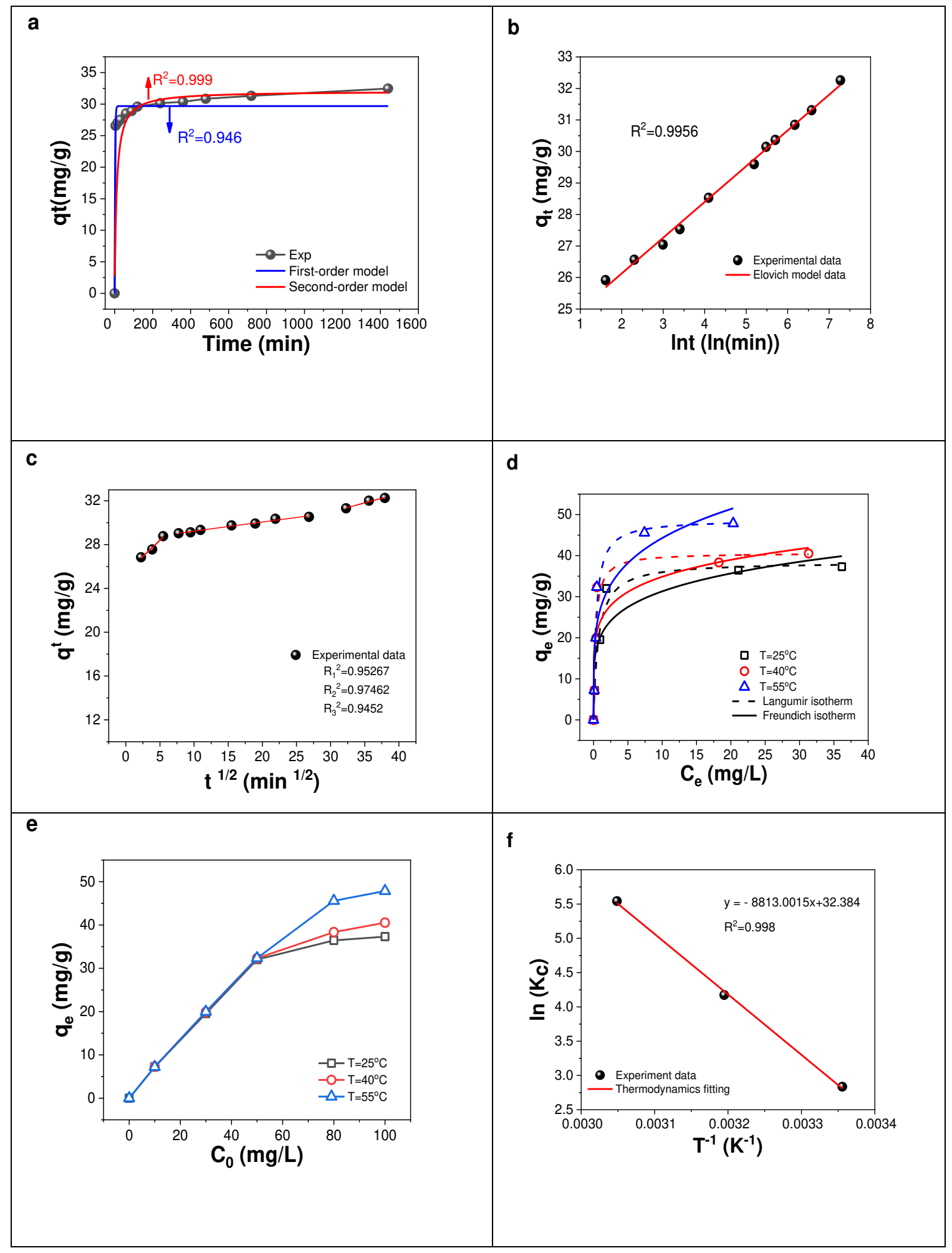

253 Fig. 4. (a) Pseudo-first order and and Pesudo-second order; (b) Elovich model; (c)

254 Intra-partice diffusion kinetic model; (d) Langmuir and Freundich adsorption isotherms;

255 (e) Effects of original concentration on adsorption capacity at different temperature;(f) 
Thermodynamic plot solution $\mathrm{pH} 5.25$, mass of adsorbent $=1.5 \mathrm{~g} / \mathrm{L}$, and $\mathrm{T}=25^{\circ} \mathrm{C}$ ).

257 3.2.3 Adsorption Isotherms

258 Two well-known adsorption isotherm models, Langmuir and Freundlich isotherm

259 models, are commonly used to describe the adsorption process (Petkovska \& Menka

260 2014). The equilibrium adsorption isotherms were investigated at three temperatures

$261\left(25,40\right.$, and $\left.55{ }^{\circ} \mathrm{C}\right)$ with different initial concentrations of $\mathrm{Cr}(\mathrm{VI})$. The relevant

262 parameters results were shown in Table S3 corresponding equations of Langmuir and

263 Freundlich isotherms are represented as follows:

$264 \quad$ Langmuir model: $\quad q_{e}=\mathrm{KQCe} /(1+\mathrm{KC} e)$

265

Freundlich model: $\quad \mathrm{q}_{e}=\mathrm{K}_{F} \mathrm{C}_{e}^{n}$

Where $\mathrm{q}_{\mathrm{e}}(\mathrm{mg} / \mathrm{g})$ is the equilibrium adsorption of $\mathrm{Cr}(\mathrm{VI})(\mathrm{mg} / \mathrm{g}), \mathrm{C}_{\mathrm{e}}(\mathrm{mg} / \mathrm{L})$ is the

267 equilibrium concentration in solution; $\mathrm{q}_{\max }(\mathrm{mg} / \mathrm{g})$ is the monolayer capacity of the

268 adsorbent; $\mathrm{K}_{\mathrm{L}}$ is the Langmuir constant related to the free energy of adsorption; $\mathrm{K}_{\mathrm{F}}$ and

$269 \mathrm{n}$ are the Freundlich constant and the heterogeneity factor, respectively.

270 In Fig. 4(d), It was obvious that the Langmuir model fitted the experimental data

271 better. According to Table S3, the correlation coefficient $\left(\mathrm{R}^{2}\right)$, compared with the

272 Freundlich model, the Langmuir model at three different temperatures showed a better

273 fitting $\left(\mathrm{R}^{2}>0.95\right)$, which indicated that the adsorption process could be explained via

274 the Langmuir model, can reflect that both physical and chemical adsorption are

275 involved in the adsorption process and the maximum adsorption capacity was about

$27648.813 \mathrm{mg} / \mathrm{g}$ at $333 \mathrm{~K}$. The results showed that the adsorption of $\mathrm{Cr}$ (VI) on the

277 adsorbent was not caused by a single factor, but affected by a variety of adsorption 278 processes.

$279 \quad 3.2 .4$ Thermodynamic study 
Thermodynamic study can reveal the feasibility and spontaneous nature of the

281 adsorption process. Thermodynamic parameters are shown in Fig. S3. and Fig. 1. As

282 shown in Fig. 4(e), with the increases in temperature, the adsorption capacity increased

283 from 7.12 to $47.85 \mathrm{mg} / \mathrm{g}$ that higher temperature was beneficial to the adsorption

284 process. When the initial concentration was more than $50 \mathrm{mg} / \mathrm{L}$, the temperature has a

285 significant effect on the removal of $\mathrm{Cr}(\mathrm{VI})$. To further explore the effect of temperature

286 on adsorption efficiency, the thermodynamic parameters are determined using the

287 following equations:

288

289

290

$$
\Delta G=-R T \ln k_{c}
$$

$$
\ln k_{c}=\frac{\Delta S}{R}-\frac{\Delta H}{R T}
$$

$$
k_{c}=\frac{q_{e}}{c_{e}}
$$

291 Tabel 1. Thermodynamic parameters at different temperatures

\begin{tabular}{cccccc}
\hline $\mathrm{T}(\mathrm{K})$ & $\mathrm{Lnk}_{\mathrm{c}}$ & $\Delta \mathrm{G}(\mathrm{kJ} / \mathrm{mol})$ & $\Delta \mathrm{H}(\mathrm{kJ} / \mathrm{mol})$ & $\Delta \mathrm{S}(\mathrm{J} /(\mathrm{mol} . \mathrm{K}))$ & $\mathrm{R}^{2}$ \\
\hline 298 & 2.835812 & -7.02593 & 73.27 & 269.2406 & 0.998 \\
313 & 4.173052 & -10.339 & & & \\
328 & 5.543335 & -13.734 & & & \\
\hline
\end{tabular}

Where $\mathrm{q}_{\mathrm{e}}$ and $\mathrm{C}_{\mathrm{e}}$ are equilibration adsorption amount and equilibration adsorbate

293 concentration, $\mathrm{R}(8.314 \mathrm{~J} / \mathrm{mol} / \mathrm{k})$ is the universal gas constant, $\mathrm{K}_{\mathrm{c}}$ is the distribution 294 coefficient at each temperature $(\mathrm{mg} / \mathrm{L})$ and $\mathrm{T}$ is the absolute temperature. Enthalpy 295 changes $(\Delta \mathrm{H})$, entropy changes $(\Delta S)$, free Gibbs energy $(\Delta G)$ are three basic 296 thermodynamics parameters associated with the adsorption process.

297 Thermodynamic constants and curves have shown in Fig. 4(e) and (f) and Table 1, 298 respectively. When the initial concentration was greater than $50 \mathrm{mg} / \mathrm{L}$, the temperature 
299 in increases significantly increased the adsorption capacity (Fig. 4(e)), and the linear

300 fitted well between $\mathrm{LnK}_{0}$ and 1/T (Fig. 4(f)) And usually, $\Delta \mathrm{H}>0$ indicated that the

301 reaction was an endothermic process. The positive $\Delta \mathrm{H}$ value of $73.27 \mathrm{~kJ} / \mathrm{mol}$ (Tabel 1)

302 indicated the adsorption of $\mathrm{Cr}(\mathrm{VI})$ was an endothermic process (Chen et al. 2011). It

303 should be noted that $\Delta \mathrm{H}$ is generally in the range of $2.1-20.9 \mathrm{KJ} / \mathrm{mol}$, which belongs to

304 physical adsorption, while the chemical interaction involving complexation is usually

305 between $20.9-418.4 \mathrm{KJ} / \mathrm{mol}$ (Rathinam et al. 2014). Therefore, the thermodynamic

306 parameters well proved that the adsorption process in this study was a chemical

307 adsorption process involving complexation. Besides, the positive $\Delta \mathrm{S}>0(296.2406$

$308 \mathrm{~J} / \mathrm{mol} / \mathrm{K}$ ) represented increasing in reaction system disorder, which was favorable to

309 the adsorption reaction. And, $\Delta \mathrm{G}<0$ manifested $\mathrm{Cr}(\mathrm{VI})$ adsorption on $\mathrm{Z}_{\mathrm{p}}-p g \mathrm{BC}$ was a

310 spontaneous reaction (Liu \& $\mathrm{Xu}$ 2007). The $\Delta \mathrm{G}$ values decreased when the

311 temperature increased, which indicated that the spontaneous degree also increased with

312 the temperature increasing.

$313 \quad 3.2 .5$ Evaluation of selective adsorption

314 To investigate the selective properties of the $\mathrm{Z}_{\mathrm{p}}-p g \mathrm{BC}-400{ }^{\circ} \mathrm{C}$, adsorption of

$315 \mathrm{Cr}(\mathrm{VI})$ in the presence of competitive ions in the binary system have been studied.

316 Because $\mathrm{Cr}(\mathrm{VI})$ existed in the form of the anion in solution, only the influence of anion

317 on its selective adsorption was studied. The concentration of $\mathrm{Cr}(\mathrm{VI})$ in all solutions

318 was $50 \mathrm{mg} / \mathrm{L}$. In Fig. 5, it can be seen that the removal efficiency of Cr(VI) was close

319 to $100 \%$ (except $\mathrm{CO}_{3}{ }^{2-}$ ) when the concentration of co-existing ions increases from 30

$320 \mathrm{mg} / \mathrm{L}$ to $100 \mathrm{mg} / \mathrm{L}$. To explore whether there was competitive adsorption between

$321 \mathrm{CO}_{3}{ }^{2-}$ and $\mathrm{Cr}$, or whether the addition of $\mathrm{CO}_{3}{ }^{2-}$ changed the inherent $\mathrm{pH}$ value of the

322 solution, the $\mathrm{pH}$ value of the solution with $\mathrm{CO}_{3}{ }^{2-}$ added was determined. The $\mathrm{pH}$ values 
323 of $30,50,100 \mathrm{mg} / \mathrm{L}$ carbonate solution and the $\mathrm{Cr}$ ion coexistence solution were 6.26 ,

3247.62 , and 10.12, respectively. When the $\mathrm{pH}$ value of the solution added with carbonate

325 was adjusted to about 5.20, the $\mathrm{Cr}(\mathrm{VI})$ removal rate was restored to nearly $100 \%$. The

326 reason was that the addition of carbonate changed the $\mathrm{pH}$ value of the solution,

327 exceeding the $\mathrm{pH}$ window, resulting in a decrease in the adsorption effect. Therefore,

328 the results indicated that the prepared $\mathrm{Z}_{\mathrm{p}}-p g \mathrm{BC}-400{ }^{\circ} \mathrm{C}$ had high selectivity towards

$329 \mathrm{Cr}(\mathrm{VI})$ in the presence of competitive ions, and it can recognize $\mathrm{Cr}_{2} \mathrm{O}_{7}^{2-}$ very well even

330 in the presence of interfering ions to a quite high extent.

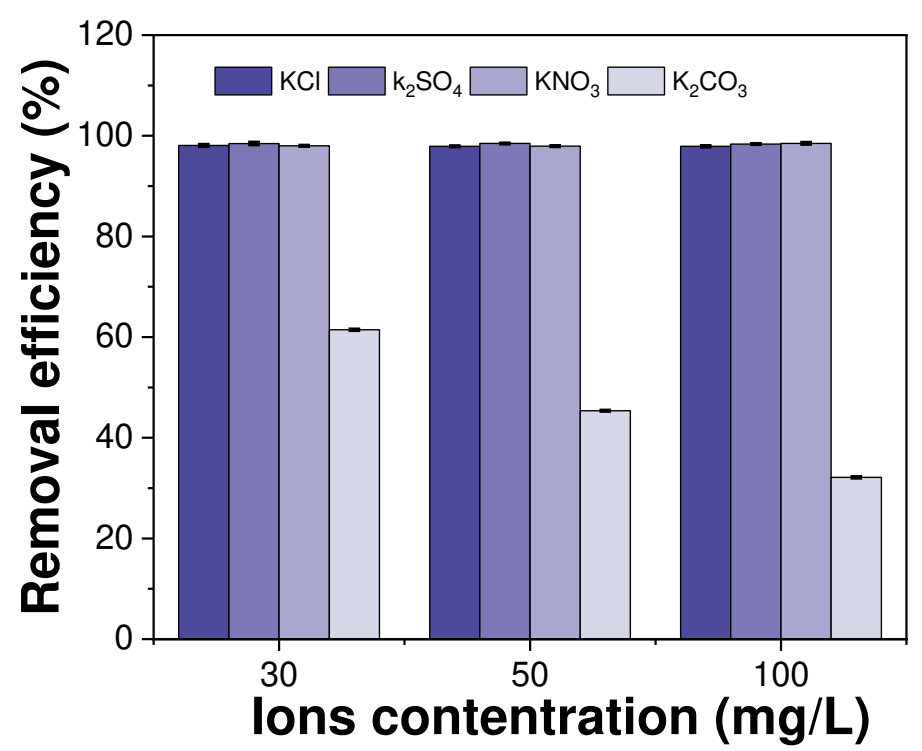

331

Fig. 5. Effect of four common co-existing ions on $\mathrm{Cr}(\mathrm{VI})$ removal efficiency

333 3.3 Characteristics and mechanism

334 3.3.1 XRD and FTIR analysis

335 Fig. 6(a) showed the XRD pattern of the adsorbed material. The strong broad 336 peaks at $23^{\circ}$ and $44^{\circ}$ correspond to the crystal planes of (002) and (100) representing 337 the typical graphitic carbon, which is often observed for pyrolyzed biomass carbons 338 (Liu et al. 2014). Fig. 6(b) showed the infrared spectra before and after adsorption, on 339 the whole, the positions of functional groups were almost unchanged before and after 
340 adsorption, which may be the reason why the adsorbent can be removed efficiently

341 after several times of adsorption and desorption. Functional groups in biochar are $-\mathrm{OH}$

$342\left(3000-3500 \mathrm{~cm}^{-1}\right), \mathrm{C}=\mathrm{O} / \mathrm{C}-\mathrm{O}-\mathrm{C}\left(1680 \mathrm{~cm}^{-1}\right),-\mathrm{CH}_{2}\left(2932,2856 \mathrm{~cm}^{-1}\right)$, etc. The

343 characteristic absorption bands at $2932 \mathrm{~cm}^{-1}$ and $2856 \mathrm{~cm}^{-1}$ belong to methylene

344 stretching and bending vibrations (Chaofan et al. 2018). The characteristic peaks at

3451680 and $1570 \mathrm{~cm}^{-1}$ were attributed to the stretching vibrations of $\mathrm{C}=\mathrm{C} / \mathrm{C}=\mathrm{O} / \mathrm{C}-\mathrm{O}-\mathrm{C}$

346 respectively due to generated polar functional groups on the $\mathrm{Z}_{\mathrm{p}}-p g \mathrm{BC}-400{ }^{\circ} \mathrm{C}$ after acid

347 functionalization. And, the peak at $1134,1057 \mathrm{~cm}^{-1}$ could be assigned to $\mathrm{P}-\mathrm{O} / \mathrm{P}=\mathrm{O}$

348 groups (Chen et al. 2018). At peaks of $898 \mathrm{~cm}^{-1}$ and $804 \mathrm{~cm}^{-1}$, new substances were

349 formed, which could be the vibration of $\mathrm{Cr}-\mathrm{O}$ ( $\mathrm{Li}$ et al. 2009). The FTIR results

350 indicated that the adsorbent contained kinds of functional groups, such as - $\mathrm{COOH}$,

$351 \mathrm{C}=\mathrm{O},-\mathrm{OH}, \mathrm{P}=\mathrm{O} / \mathrm{P}-\mathrm{O}$, and $\mathrm{R}-\mathrm{C}-\mathrm{O}-\mathrm{C}$, which could provide numerous actives sites.

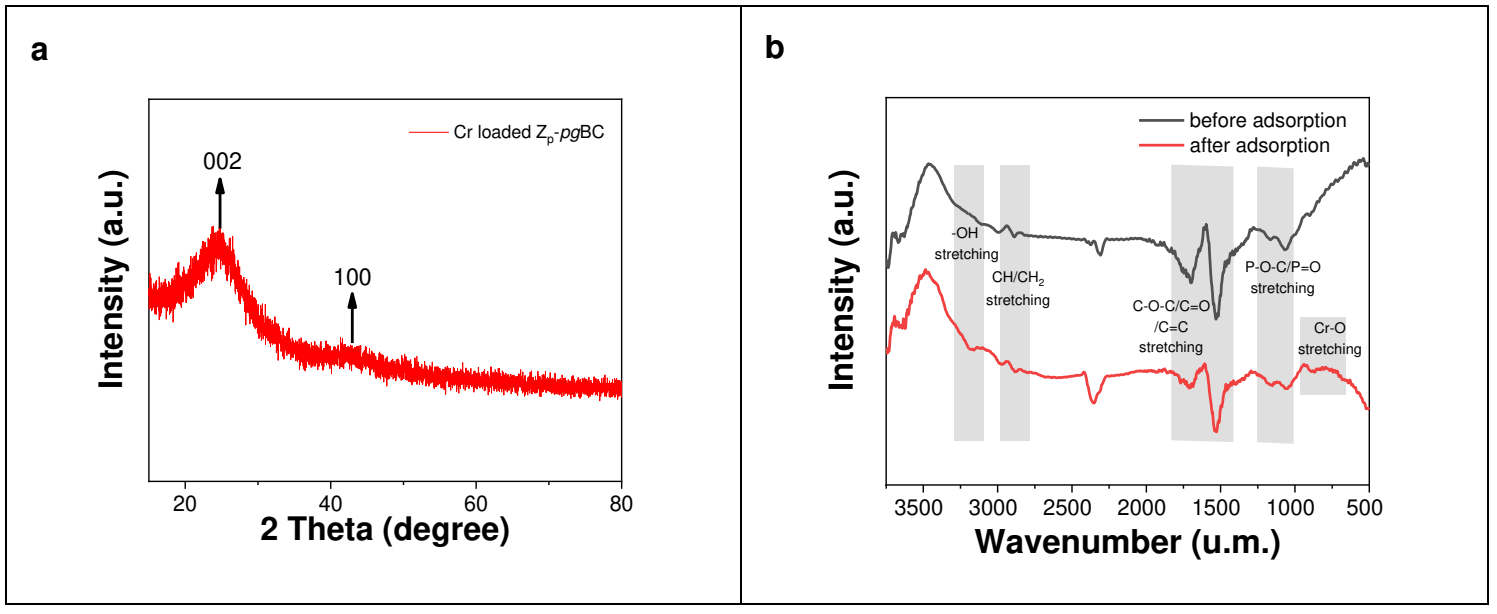

Fig. 6. (a) XRD patterns, (b) FTIR spectra of $\mathrm{Z}_{\mathrm{p}}-p g B C-400^{\circ} \mathrm{C}$.

353 3.3.2 Structure and Morphology analysis

354 SEM is widely used to study the morphological and surface characteristics of the

355 adsorbent materials. The surface morphological of raw materials (Pennisetum

356 giganteum) and $\mathrm{Z}_{\mathrm{p}}-p g \mathrm{BC}-400{ }^{\circ} \mathrm{C}$ before and after adsorption are shown in Fig. 7. It can

357 be observed that Fig. 7(a) presented a compact structure with low porosity and a 
smooth surface. However, after mixed with phosphoric acid impregnation (Fig. 7(b) and Fig. 7(c)), the surface looked very rough with irregular cavities structure. This

360 structural change may be due to the addition of phosphoric acid, a large number of

361 irregular groups were introduced. From adsorption, this structure is conducive to

362 adsorption. Moreover, for the difference between Fig. 7(c) and (b), which may be the

363 result of the reaction between $\mathrm{Cr}$ and oxygen-containing functional groups on carbon

364 materials. The rich distribution of $\mathrm{C}, \mathrm{O}$, and $\mathrm{P}$ elemental indicates the existence of a

365 large number of oxygen-containing functional groups and Phosphorus oxygen

366 functional groups on the $\mathrm{Zp}-\mathrm{pgBC}-400{ }^{\circ} \mathrm{C}$ surface. Besides, the uniform distribution of

367 chromium in Fig. 7(g) indicated that $\mathrm{Cr}(\mathrm{VI})$ was successfully adsorbed on the surface

368 of $\mathrm{Z}_{\mathrm{p}-p g B C}-400{ }^{\circ} \mathrm{C}$. The EDS mapping analysis results of $\mathrm{Z}_{\mathrm{p}}-p g \mathrm{BC}-400{ }^{\circ} \mathrm{C}$ after

369 adsorbing of $\mathrm{Cr}(\mathrm{VI})$ have been described in Fig. 7(d-g). Mapping results showed that

370 that $\mathrm{Cr}(\mathrm{VI})$ contaminants have been homogeneously distributed. And the element

371 content in Fig. 7(i). The prepared carbon materials have a large specific surface area

$372\left(749.9 \mathrm{~m}^{2} / \mathrm{g}\right)$, large pore volume, rod-like porous structure, abundant $\mathrm{P}$ atoms, and

373 abundant oxygen-containing functional groups.

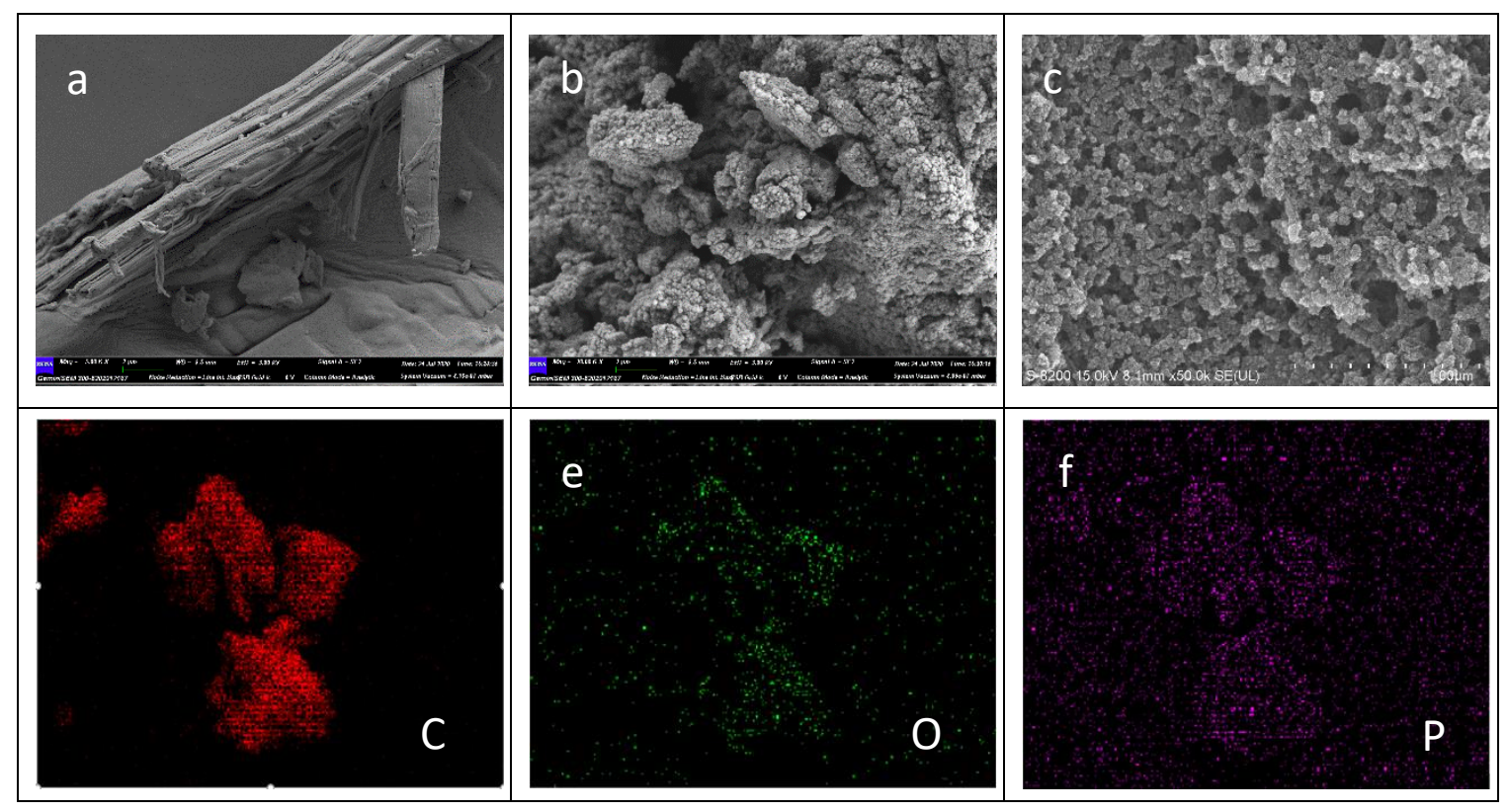




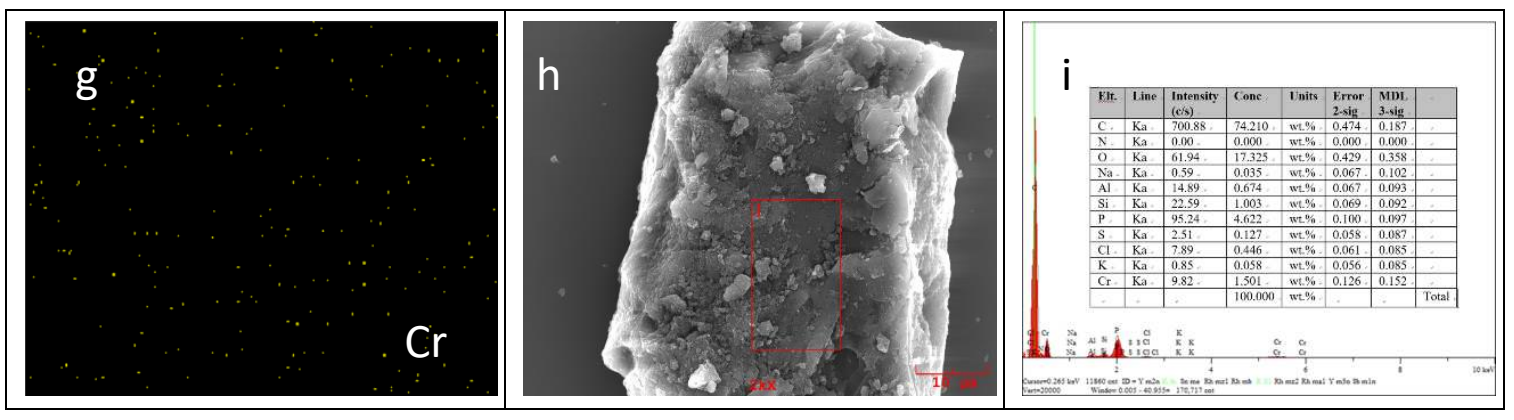

374 Fig. 7 SEM images of Pennisetum giganteum (a); $\mathrm{Z}_{\mathrm{p}}-p g \mathrm{BC}-400{ }^{\circ} \mathrm{C}$ before (b) and after

375 (c) Cr adsorption; Elemental mapping of (d) C, (e) O, (f) P, (g) Cr; (h) EDS point scan analysis area and (j) the corresponding EDS patterns.

\subsubsection{XPS and morphology analysis}

Besides element composition, XPS can also provide information on their valences

of adsorbent and adsorbed species. The fine spectrum of $\mathrm{C}_{1 \mathrm{~s}}$ (Fig. 8 (a)) can be fitted to 3 peaks centered on the binding energies of about $\sim 284.6 \mathrm{eV}, \sim 286.0 \mathrm{eV}$, and $\sim 289.4 \mathrm{eV}$, corresponding to the presence of $\mathrm{C}-\mathrm{C}, \mathrm{C}-\mathrm{O} / \mathrm{C}-\mathrm{P}$, and $\mathrm{C}=\mathrm{O}$ bonds, respectively (Chen et al. 2018). The binding energy position and relative content of carbon changed little before and after use, indicating that the chemical state of the $\mathrm{C}$ element in biochar is relatively stable. Three peaks at about $\sim 530 \mathrm{eV}, \sim 532 \mathrm{eV}$, and $\sim 534 \mathrm{eV}$ in Fig.8(b) represented of $\mathrm{C}=\mathrm{O} / \mathrm{P}=\mathrm{O}, \mathrm{C}-\mathrm{O} / \mathrm{P}-\mathrm{O}$, and $-\mathrm{OH} / \mathrm{H}_{2} \mathrm{O}$ (Chen et al. 2020; $\mathrm{Li}$ et al. 2020). And, the $\mathrm{O}$ elements in the adsorption after also could observe three peaks. It is worth noting that the content of $\mathrm{C}-\mathrm{O} / \mathrm{P}-\mathrm{O}(\sim 532 \mathrm{eV})$ decreased, which indicated that the $\mathrm{C}-\mathrm{O} / \mathrm{P}-\mathrm{O}$ bond was oxidized to $\mathrm{C}=\mathrm{O} / \mathrm{P}=\mathrm{O}$ during the reaction ( $\mathrm{Xu}$ et al. 2019a; $\mathrm{Zhou}$ et al. 2016b). And the binding energy of $\mathrm{O}$ shifted positively after the reaction, which

390 indicated that the electron cloud density of $\mathrm{O}$ decreased, resulting in the detection of a

391 higher binding energy band. In the process of $\mathrm{Cr}$ (VI) reduction, the $\mathrm{O}$ atom was the 392 electron donor (Gao et al. 2013). This indicated that C-O/P-O participates in the 393 adsorption and reduction of $\mathrm{Cr}(\mathrm{VI})$. Also, the fine spectrum of $\mathrm{P}_{2 p}$ has been changed 
394 significantly. Attentively, for the phosphorus species, the strength of $\mathrm{Z}_{\mathrm{p}}-p g \mathrm{BC}-400{ }^{\circ} \mathrm{C}$

395 decreased significantly after adsorption. And, the proportion of C-P decreased while $396 \mathrm{C}-\mathrm{P}=\mathrm{O}$ increased. The increase of $\mathrm{C}-\mathrm{P}=\mathrm{O}$ content indicated that after adsorption of $\mathrm{Cr}$ 397 on biochar, the C-P bond of biochar was broken and the $\mathrm{P}=\mathrm{O}$ bond was formed with 398 chromate to form chromium phosphate. After adsorption, a new peak of $\mathrm{CrPO}_{4}$ 399 appeared at the binding energy of $133.4 \mathrm{eV}$ (Fig. 8 (c)), which indicated that the 400 P-containing group can interact and precipitate with some $\mathrm{Cr}$ (VI) ions. The fine 401 spectra of $\mathrm{Cr}(\mathrm{VI})$ are shown in Fig. 8(d). Binding energies at $578.06 \mathrm{eV}$ and $587.47 \mathrm{eV}$ 402 were assigned to $\mathrm{Cr} 2 \mathrm{P}_{3 / 2}$ and $2 \mathrm{P}_{1 / 2}$ orbitals of $\mathrm{Cr}(\mathrm{III})$, respectively (Xu et al. $2019 \mathrm{~b}$; 403 Zhou et al. 2016a). The small peak at $582.21 \mathrm{eV}$ was unreduced hexavalent chromium. 404 Finally, in Fig. S2, the strength of $\mathrm{C}_{1 \mathrm{~s}} / \mathrm{O}_{1 \mathrm{~s}} / \mathrm{P}_{2 \mathrm{P}}$ decreased after adsorption can be 405 observed, and $\mathrm{Cr}_{2 \mathrm{p}}$ appeared near $577 \mathrm{eV}$, further indicating that $\mathrm{Cr}$ was successfully 406 adsorbed on the surface of biochar during the adsorption process.

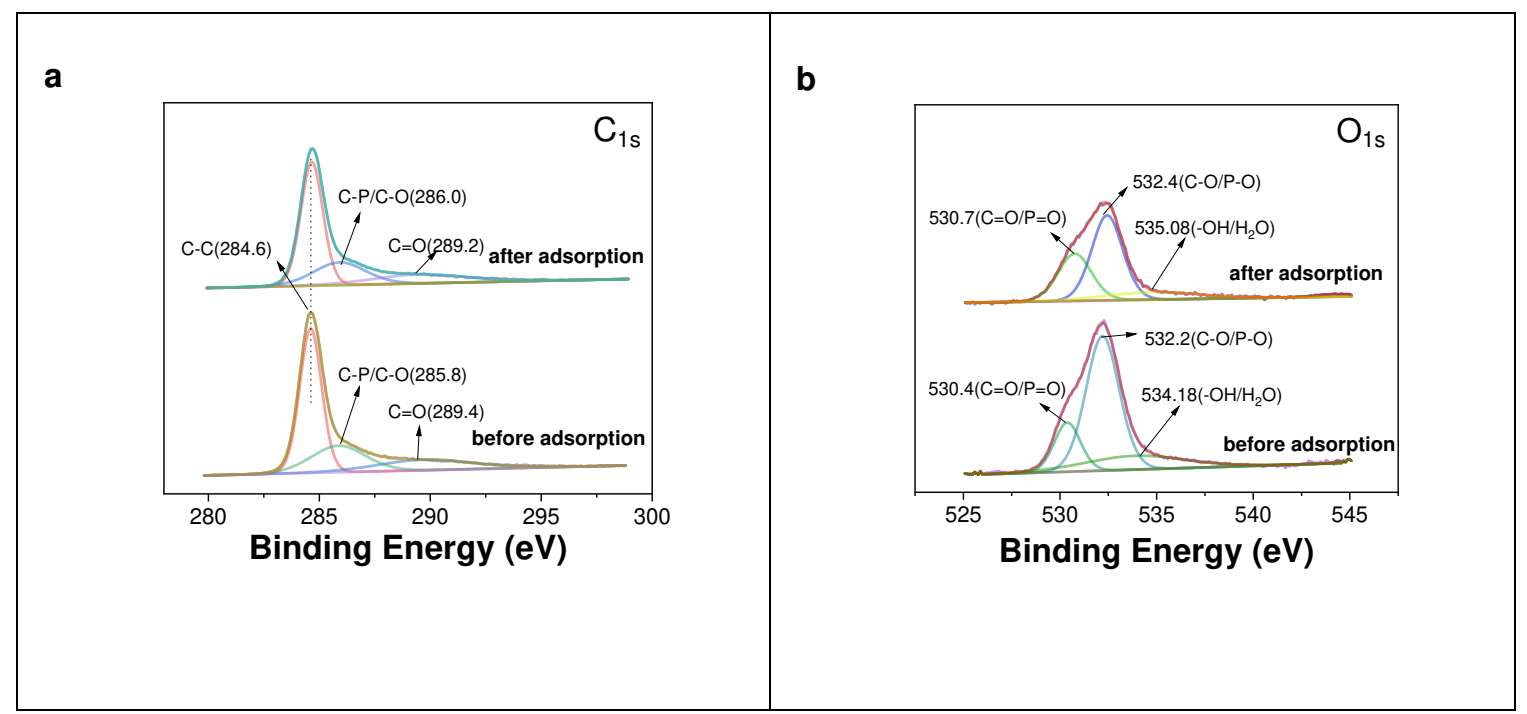




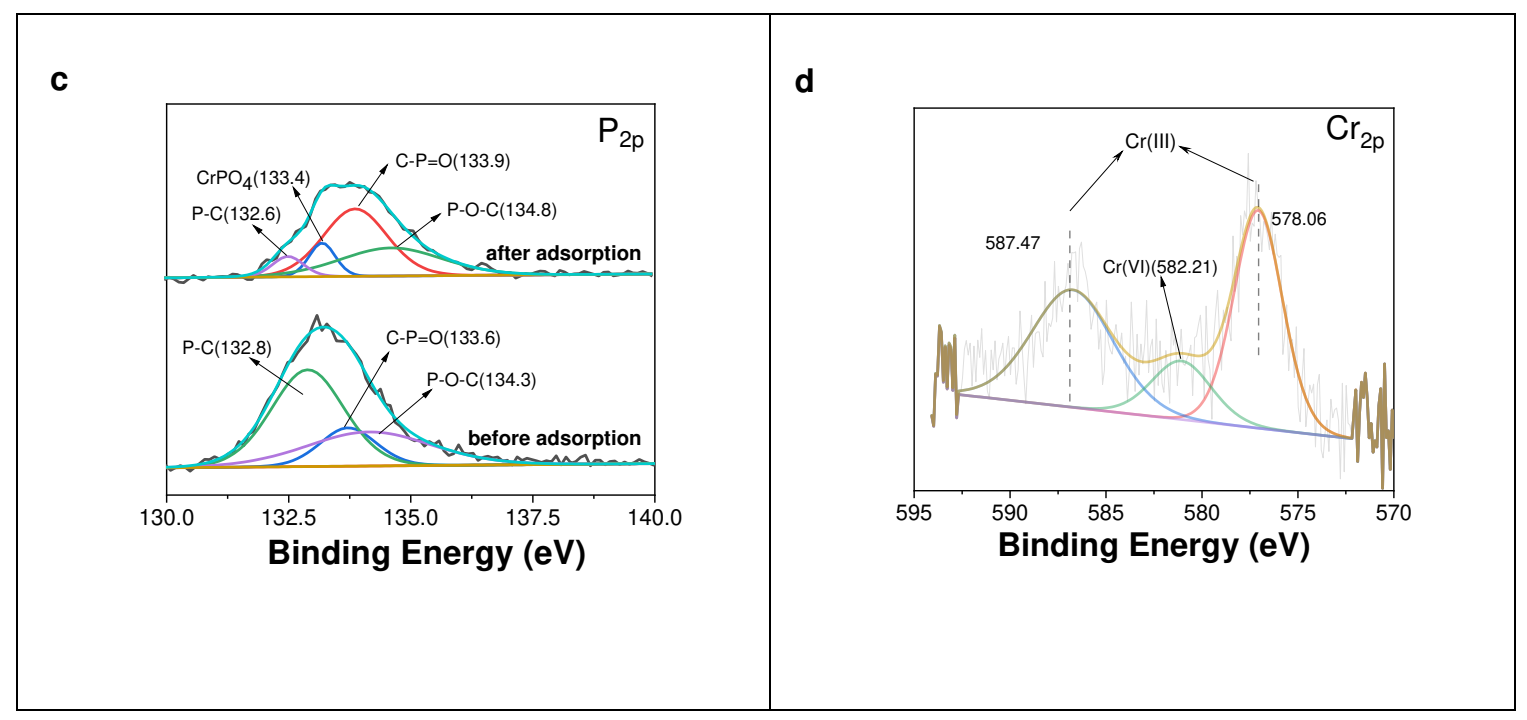

Fig. 8. XPS spectrum of $\mathrm{Zp}-p g \mathrm{BC}-400{ }^{\circ} \mathrm{C}$ before and after $\mathrm{Cr}(\mathrm{VI})$ adsorption.

(a) $\mathrm{C}_{1} \mathrm{~s}$, (b) $\mathrm{O}_{1 \mathrm{~s}}$ and (c) $\mathrm{P}_{2 \mathrm{p}}$ and (d) $\mathrm{Cr}_{2 \mathrm{p}}$.

411 adsorption-desorption cycles were performed under the optimal conditions mentioned

412 above. The details were as follows: before reusing, the used adsorbent should be

413 filtered, then immersed in $0.1 \mathrm{M} \mathrm{NaOH}$ solution, stirred for $24 \mathrm{~h}$, and then filtered and

414 dried overnight in an oven at $80{ }^{\circ} \mathrm{C}$. The results of five cycles were shown in Fig. 9.

415 The removal efficiency of $\mathrm{Cr}(\mathrm{VI})$ decreased from $99.03 \%$ to $77.74 \%$ after cycles five

416 times. After the fifth cycle, the $\mathrm{Cr}$ removal efficiency was more than $77 \%$, which

417 indicated that the synthesized adsorbent can be used many times without a significant

418 decrease in adsorption capacity. This was much better than the stability after four uses

419 reported by our research team (less than 70\%) (Guan et al. 2020).

420 The results showed that $\mathrm{Cr}(\mathrm{VI})$ can be removed by the adsorption/reduction

421 process in a wide range of operating $\mathrm{pH}$. Based on the above analysis, the adsorption

422 mechanism was proposed and systematically investigated (Fig. 10). There were many

423 acidic groups on the surface of $\mathrm{Z}_{\mathrm{p}}-p g \mathrm{BC}-400{ }^{\circ} \mathrm{C}$, such as phosphate, carboxyl, carbonyl, 
424 and so on. These acidic groups can release protons to maintain $\mathrm{pH}$ in a relatively

425 narrow range when the external environment solution $\mathrm{pH}$ is relatively high. This can

426 explain that the adsorbent can reach more than half of the removal rate under alkaline

427 conditions. To sum up, the removal mechanism was shown in Fig.10, including (1)

428 electrostatic attraction; (2) physical adsorption in porous structures; (3) chemical

429 reduction and adsorption, the most main adsorption process; and (5) metal

430 complexation. The combined action of various functions is the reason why the

431 adsorbent can effectively remove $\mathrm{Cr}(\mathrm{VI})$.

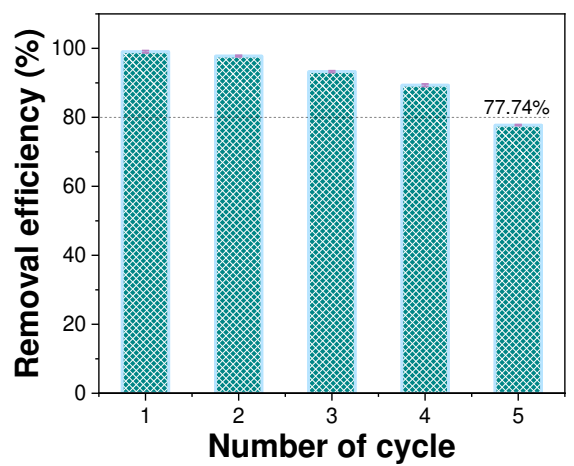

Fig. 9. Cycle times of $\mathrm{Z}_{\mathrm{p}}-p g \mathrm{BC}-400{ }^{\circ} \mathrm{C}$ on $\mathrm{Cr}(\mathrm{VI})$ removal efficiency

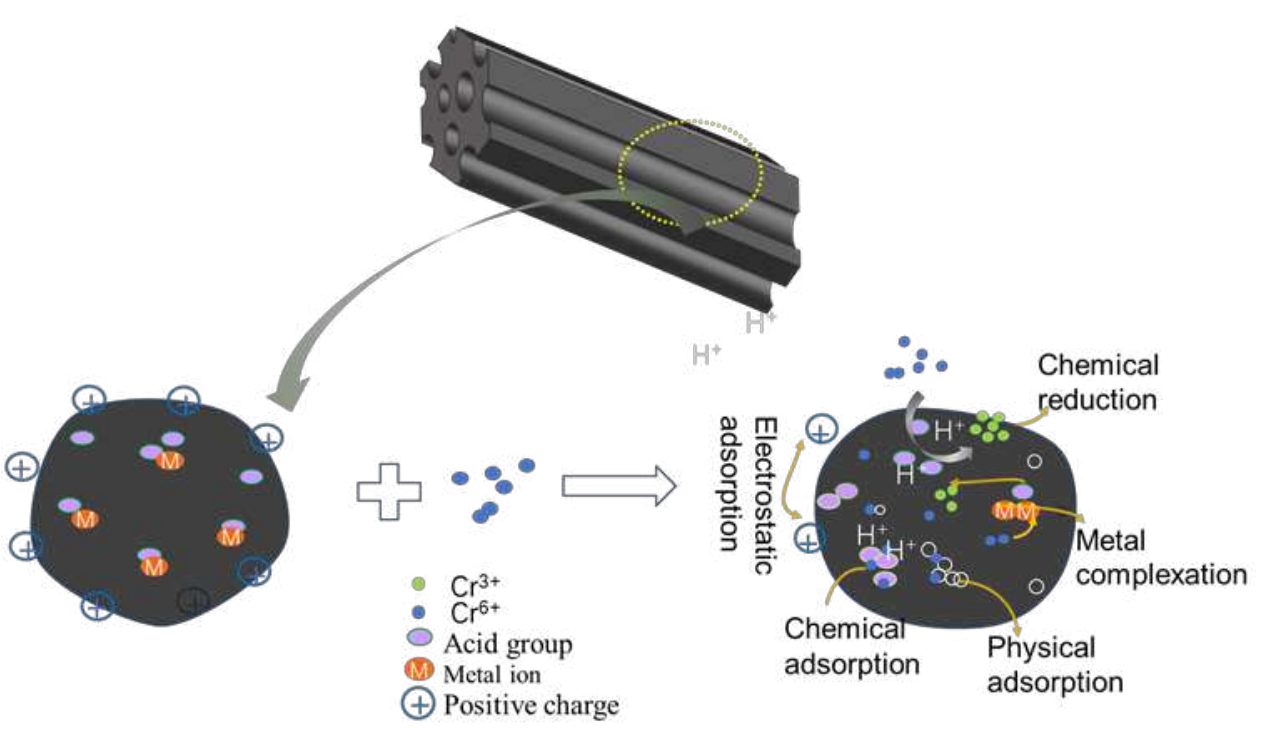

Fig. 10. Schematic illustration of $\mathrm{Cr}(\mathrm{VI})$ removal mechanism

In this paper, biochar with enough acidic surface groups was synthesized, which 
maintained the $\mathrm{pH}$ value of the system in a relatively stable range during the adsorption

439 process. $\mathrm{Cr}(\mathrm{VI})$ uptake experiments displayed that in a wide $\mathrm{pH}$ range (1-6), the

440 removal rate of $\mathrm{Cr}(\mathrm{VI})$ in water by biochar is as high as $86.39 \%$. The mechanism

441 analysis showed that the rich oxygen-containing functional groups on the surface of

442 biochar could keep the $\mathrm{pH}$ value of the solution at 3.1-5.41 when the initial $\mathrm{pH}$ value

443 was $3.04-8.98$. The maximum adsorption capacity can reach $48.813 \mathrm{mg} / \mathrm{g}$, and it is 444 accorded with pseudo-second-order kinetics and L-type adsorption model. The results

445 of five times adsorption-desorption experiments showed that the activated biochar

446 directly impregnated with phosphoric acid had good stability. This work provided an

447 effective solution for the removal of chromium in the $\mathrm{pH}$ range of a large window and

448 opened up a new way for the resource utilization of Pennisetum giganteum, a common

449 agricultural and forestry waste.

450

451 Ethical Approval

452 Not applicable

453 Consent to Participate

454 Not applicable

455 Consent to Publish

456 Consent

457 Authors Contributions

458 Chenyao : Conceptualization, Validation, Formal analysis, Data curation, writing 459 original draft. Ningping: Supervision, Project administration, Funding 460 acquisition.Miaorongrong: Draft modification.Heliang: Investigation, Methodology, 461 Writing-review \& editing.Guanqingqing: Supervision, Project administration, Funding 
acquisition.

\section{$463 \quad$ Funding}

464 This work is co-supported by the National Natural Science Foundation of China 465 (Grant No. 21968014), the Analysis and Testing Foundation of Kunming University of 466 Science and Technology (No.2019M2018220705) , and the National Key Research 467 and Development Program of China (Grant No. 2018YFC1902105, 2018YFC1902102, 468 and 2018YFC1902101).

\section{Competing Interests}

470 The authors declare that they have no known competing financial interests or 471 personal relationships that could have appeared to influence the work reported in this 472 paper.

\section{Availability of data and materials}

474 The datasets used and/or analysed during the current study are available from the 475 corresponding author on reasonable request.

476 All data generated or analysed during this study are included in this published 477 article [and its supplementary information files].

\section{References}

Ahmadi, M., Kouhgardi, E., Ramavandi, B. 2016. Physico-chemical study of dew melon peel biochar for chromium attenuation from simulated and actual wastewaters. Korean Journal of Chemical Engineering, 33(9), 2589-2601. 

of citalopram from water. Bioresour Technol, 166, 335-44. solution. Rsc Advances, 5. performance toward Cr(VI). Bioresource Technology, 267, S0960852418309118-. adsorption/reduction of aqueous $\mathrm{Cr}(\mathrm{VI})$ using biochar from directly treated jute (Corchorus Enhanced $\mathrm{Cr}(\mathrm{VI})$ removal by polyethylenimine- and phosphorus-codoped hierarchical porous carbons. Journal of Colloid and Interface Science, 523, 110-120. solution using modified corn stalks: Characteristic, equilibrium, kinetic and thermodynamic study. Chemical Engineering Journal, 168(2), 909-917. chromium removal by biochar from sugar beet tailing. J Hazard Mater, 190(1-3), 909-15. 190(1-3), 909-915. 
porous, surface chemistry and adsorption properties of carbon derived from Enteromorpha prolifera activated by H4P2O7 and KOH. Chemical Engineering Journal, 232, 582-590. sludge: Preparing activated carbon for efficient adsorption of $\mathrm{Cr}(\mathrm{VI})$ and further hydrogenation of furfural. ence of The Total Environment, 741, 140265. Solution. Journal of Chemical \& Engineering Data. (VI) from aqueous solution. Journal of Colloid and Interface Science, 455, 125-133. Remediating Contaminated Soil. co-doped biochars from (NH4)(3)PO4-pretreated coffee shells and appraisement for remedying aqueous $\mathrm{Cr}(\mathrm{VI})$ contaminants. Bioresource Technology, 315. Water Research, 43(12), 3067-3075. three-dimensional honeycomb carbon materials and their adsorption of $\mathrm{Cr}(\mathrm{VI})$ (vol 367, pg 9, 2019). Chemical Engineering Journal, 387.

Liu, H., Liang, S., Gao, J., Huu Hao, N., Guo, W., Guo, Z., Wang, J., Li, Y. 2014. Enhancement of $\mathrm{Cr}(\mathrm{VI})$ removal by modifying activated carbon developed from Zizania 
caduciflora with tartaric acid during phosphoric acid activation. Chemical Engineering Journal, 246, 168-174. biosorption by aerobic granules. Biochemical Engineering Journal, 35(2), 174-182. Concentrations via Ion Chromatography and UV-Vis Spectrophotometry in Samples Collected from Nacogdoches Wastewater Treatment Plant, East Texas (USA). Advances in Environmental Chemistry, 2016, 1-10.

Petkovska, Menka. 2014. Discrimination between adsorption isotherm models based on nonlinear frequency response results. Adsorption-journal of the International Adsorption Society, 20(2-3), 385-395. array optimization. Korean Journal of Chemical Engineering, 31(12), 2207-2214. Journal of Biological Macromolecules. 

Conference. environment by adsorption. Ecotoxicology \& Environmental Safety, 150(APR.), 1-17. carbon from coffee waste for the reclamation of effluents containing $\mathrm{Cr}(\mathrm{VI})$ ions. Journal of Industrial and Engineering Chemistry, 60, 418-430. ence: Water Research \& Technology.

Wang, Y. 2018. Characteristics of biochars from different sources and their removal mechanism of heavy metal ions, Shanghai Jiaotong University. experiment, kinetic and mechanism studies. Bioresource Technology. lanthanum doped biochars derived from lignocellulosic wastes for efficient phosphate removal and regeneration. Bioresource Technology, 289. 
biochar derived from mixture biomass precursors of Acorus calamus Linn. and feather waste. Journal of Analytical and Applied Pyrolysis, 140, 86-92. from aqueous solution by $\mathrm{FeCl} 3$ and $\mathrm{ZnCl} 2$-modified corn stalks biochar: Implicit mechanism and application. Bioresource Technology, 297. of $\mathrm{Cr}(\mathrm{VI})$ from aqueous solution using exfoliated LDH nanosheets. Colloids and Surfaces a-Physicochemical and Engineering Aspects, 520, 399-408. hexavalent chromium removal by corn-bran residue and derived chars. Rsc Advances, 5(23), 17768-17774. and coadsorption mechanisms of $\mathrm{Cr}(\mathrm{VI})$ and organic contaminants on $\mathrm{H} 3$ PO 4 treated biochar. Chemosphere, 186(nov.), 422-429.

Zhou, L., Liu, Y., Liu, S., Yin, Y., Zeng, G., Tan, X., Hu, X., Hu, X., Jiang, L., Ding, Y. 2016a. Investigation of the adsorption-reduction mechanisms of hexavalent chromium by ramie biochars of different pyrolytic temperatures. Bioresource Technology, 218, 351-359. 
Figures

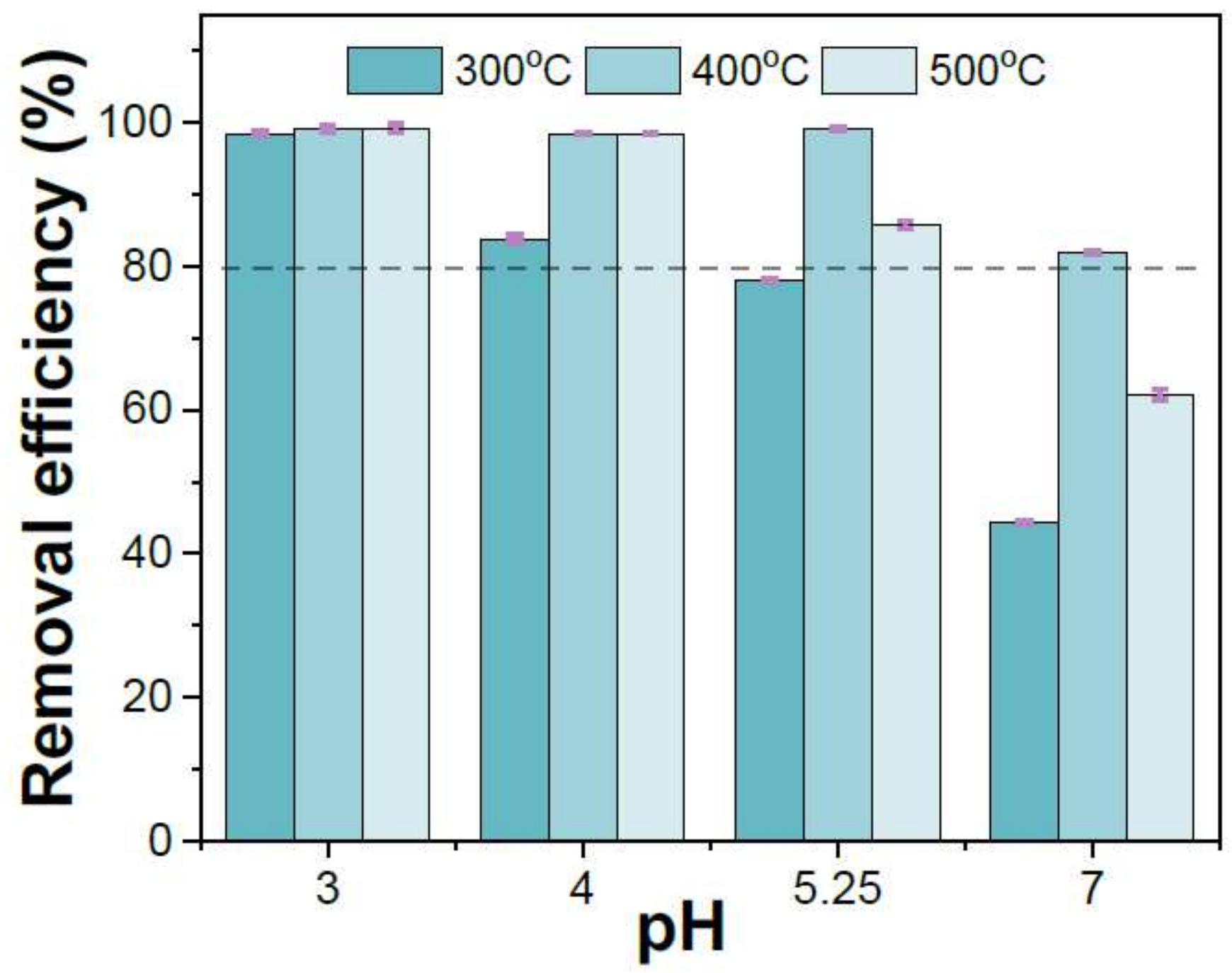

Figure 1

$\mathrm{Cr}(\mathrm{VI})$ removal efficiency at three activation temperatures. (Initial concentrations $=50 \mathrm{mg} / \mathrm{L}$, Solution $\mathrm{pH}$ 5.25 , and $\left.\mathrm{T}=25^{\circ} \mathrm{C}\right)$. 


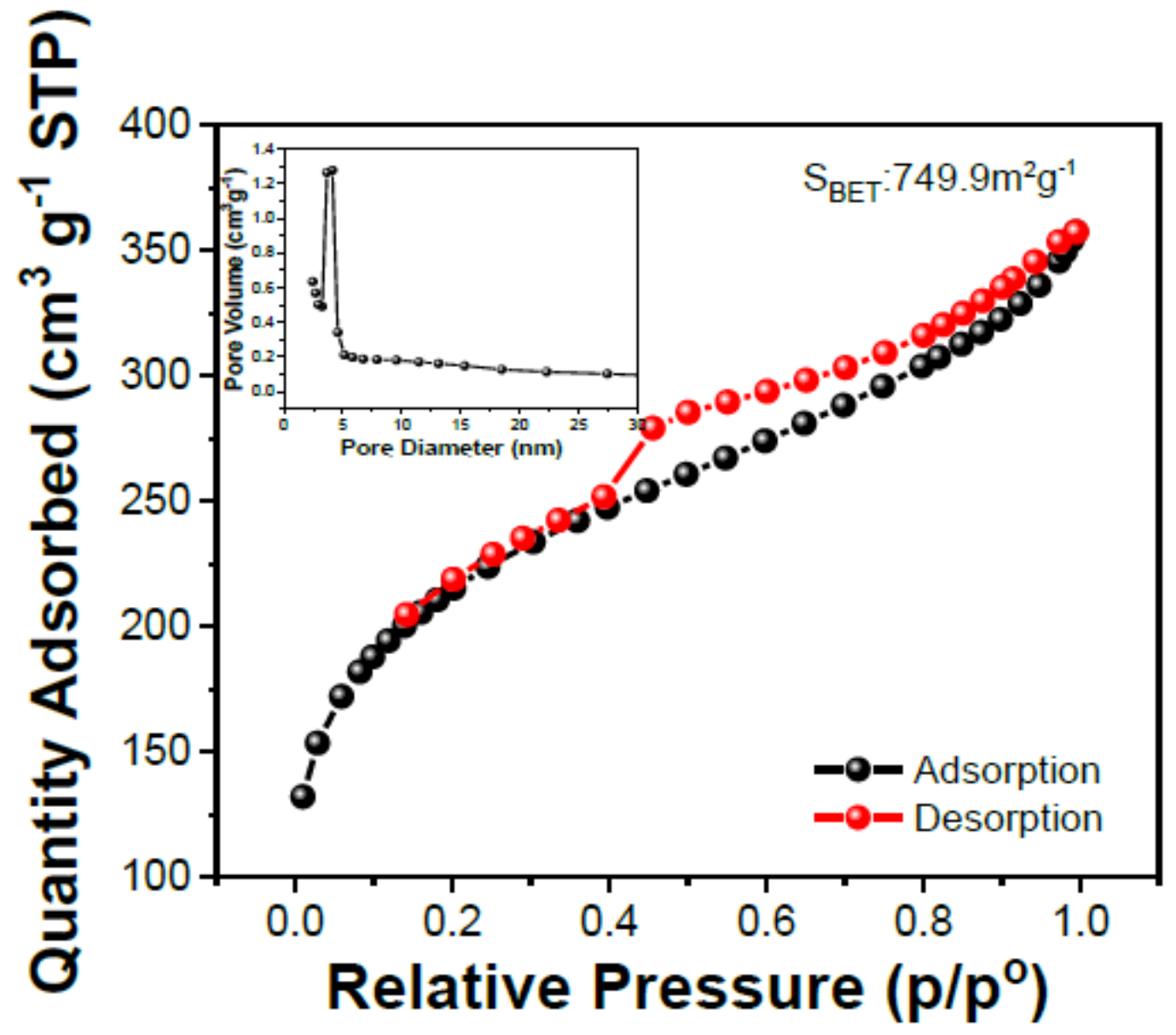

Figure 2

$\mathrm{N} 2$ adsorption/desorption isotherms and pore size distribution curve of $\mathrm{Zp}-\mathrm{pgBC}-400^{\circ} \mathrm{C}$. 


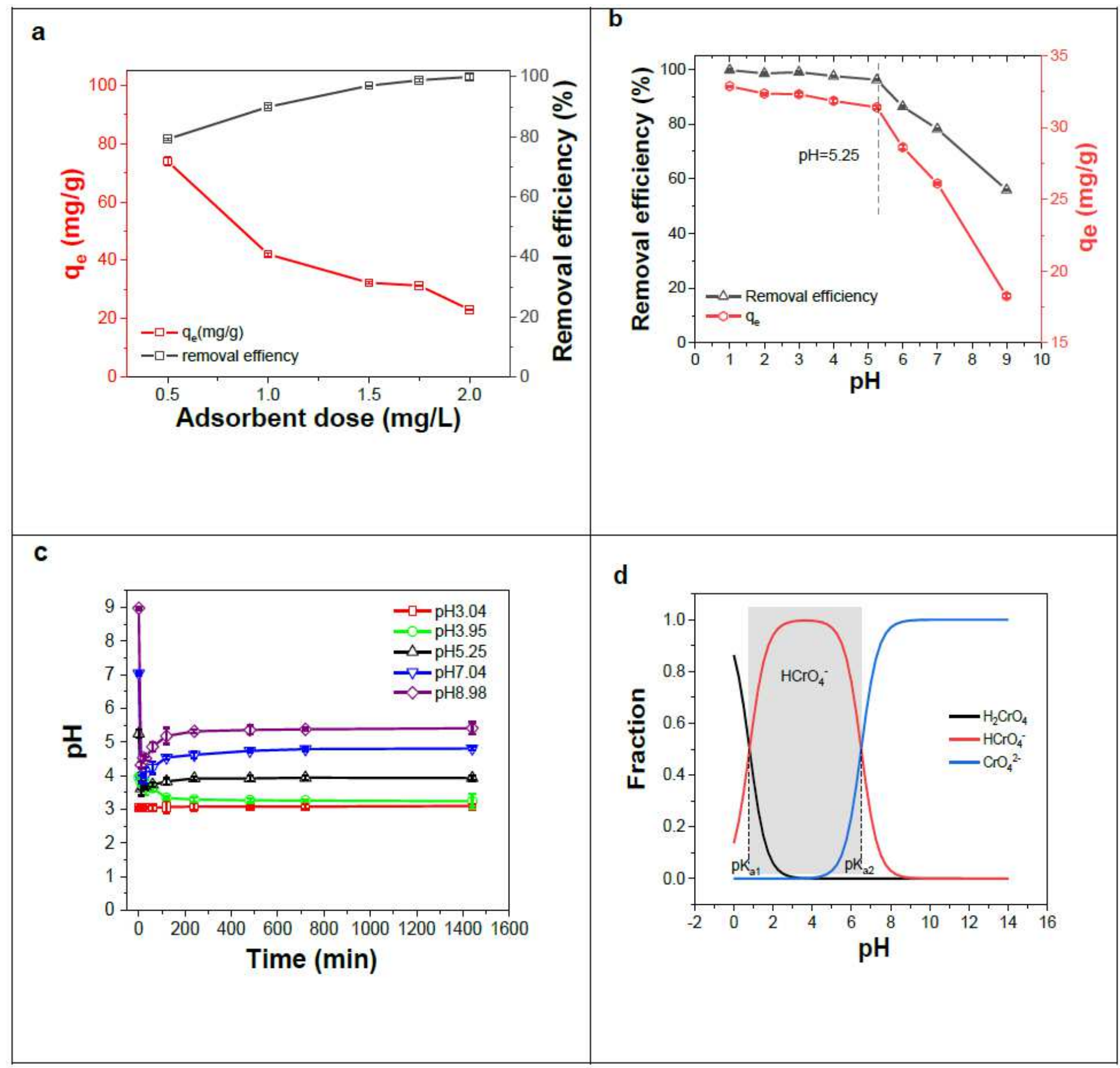

Figure 3

Effect of dosage (a) and solution $\mathrm{pH}(\mathrm{b})$ on $\mathrm{Cr}(\mathrm{VI})$ removal; (c) pH changing trend during reaction under various initial $\mathrm{pH}$ (5.25 was the intrinsic $\mathrm{pH}$ of the solution). $\mathrm{T}=298 \mathrm{~K}, \mathrm{CO}(\mathrm{VI})=50 \mathrm{mg} / \mathrm{g}, \mathrm{rpm}=160$ 


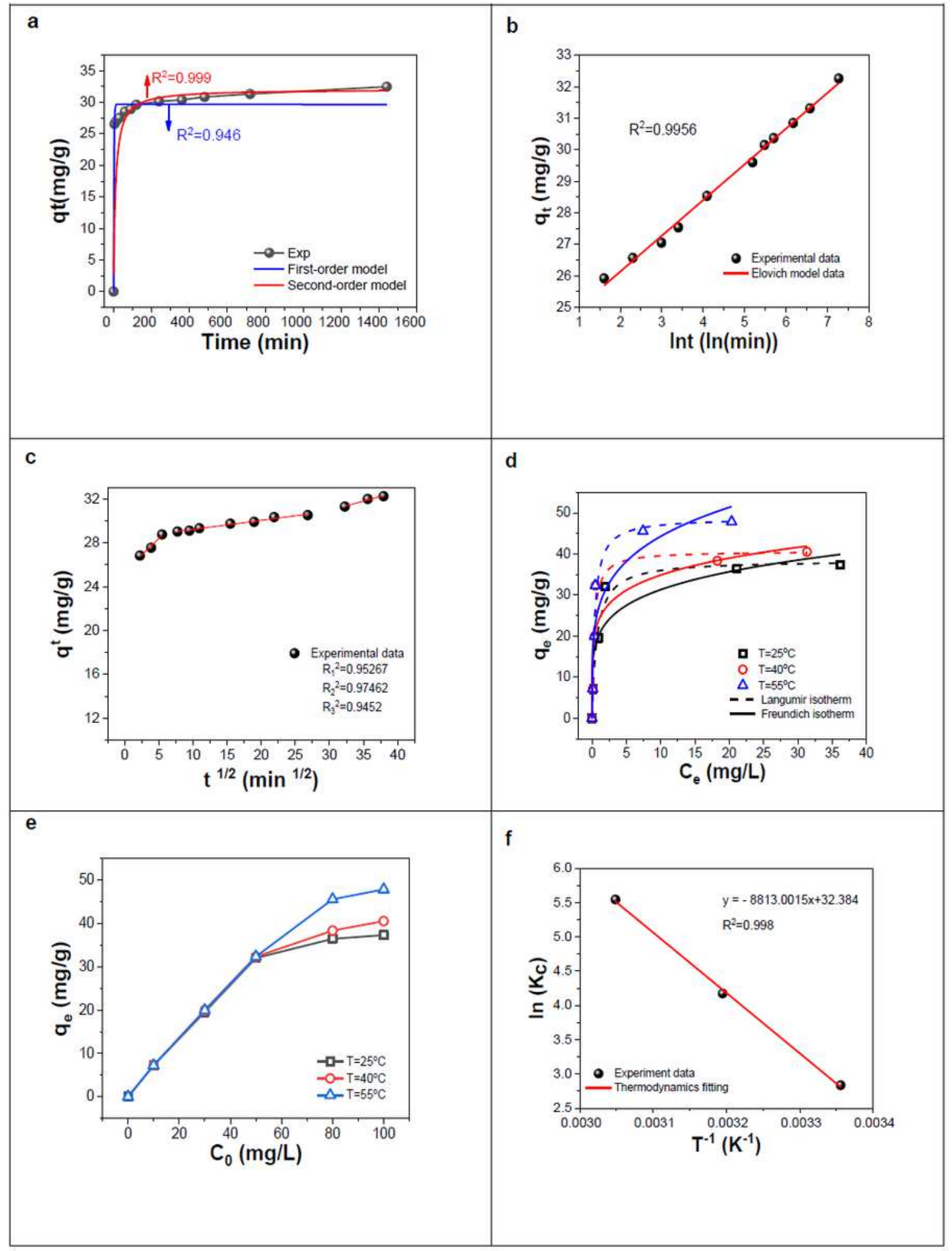

\section{Figure 4}

(a) Pseudo-first order and and Pesudo-second order; (b) Elovich model; (c) Intra-partice diffusion kinetic model; (d) Langmuir and Freundich adsorption isotherms; (e) Effects of original concentration on adsorption capacity at different temperature;(f)Thermodynamic plot solution $\mathrm{pH} 5.25$, mass of adsorbent $=1.5 \mathrm{~g} / \mathrm{L}$, and $\mathrm{T}=25^{\circ} \mathrm{C}$ ). 


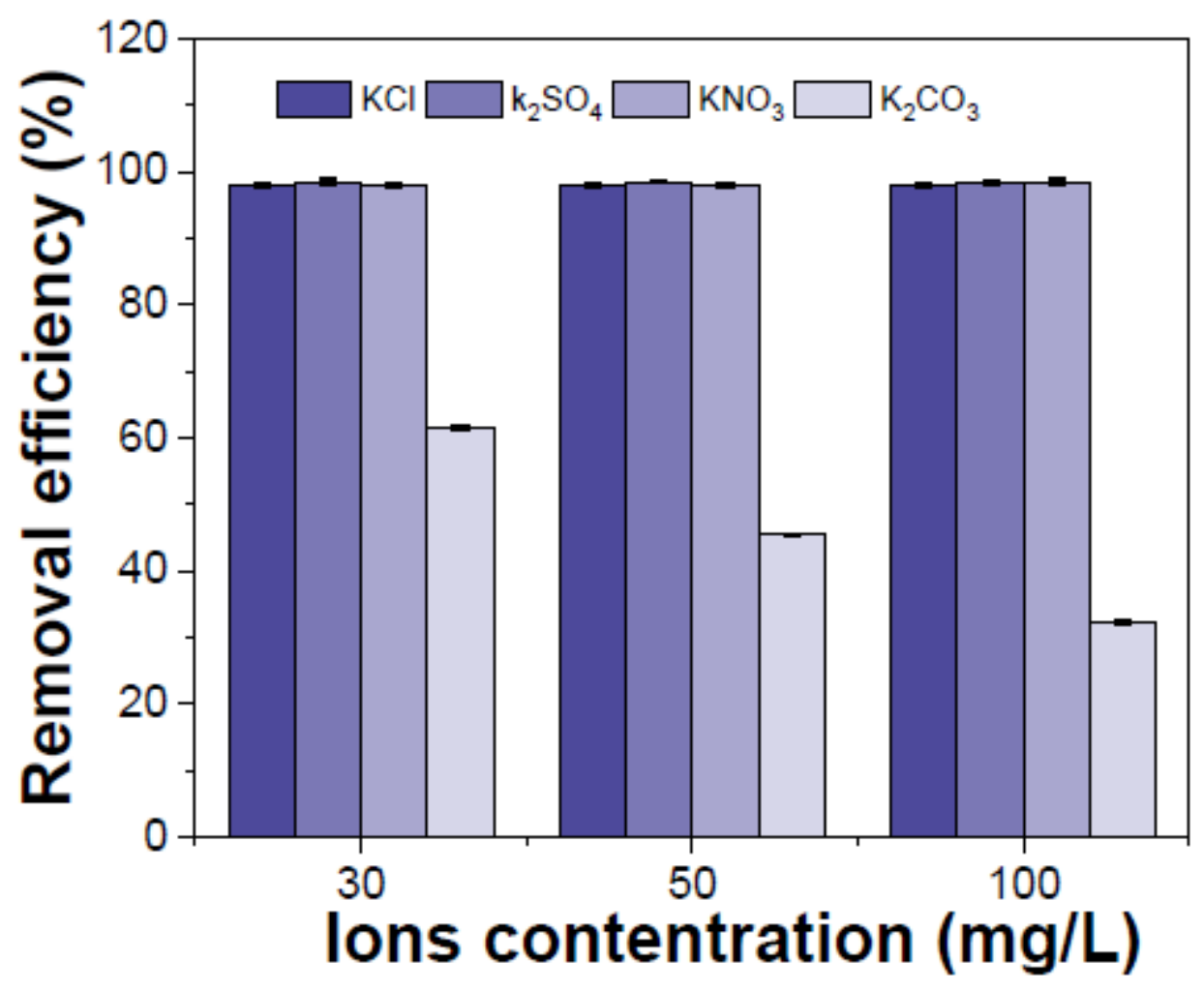

Figure 5

Effect of four common co-existing ions on $\mathrm{Cr}(\mathrm{VI})$ removal efficiency

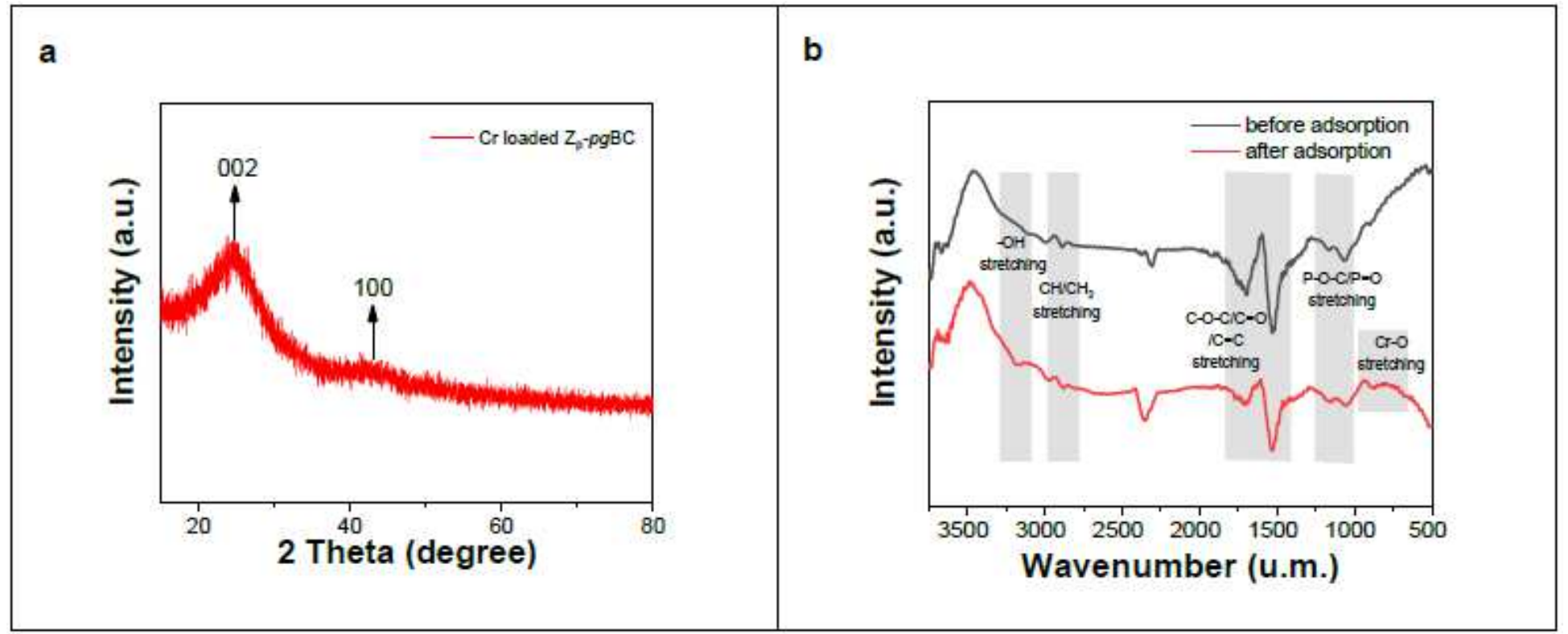

Figure 6

(a) XRD patterns, (b) FTIR spectra of Zp-pgBC- $400^{\circ} \mathrm{C}$. 


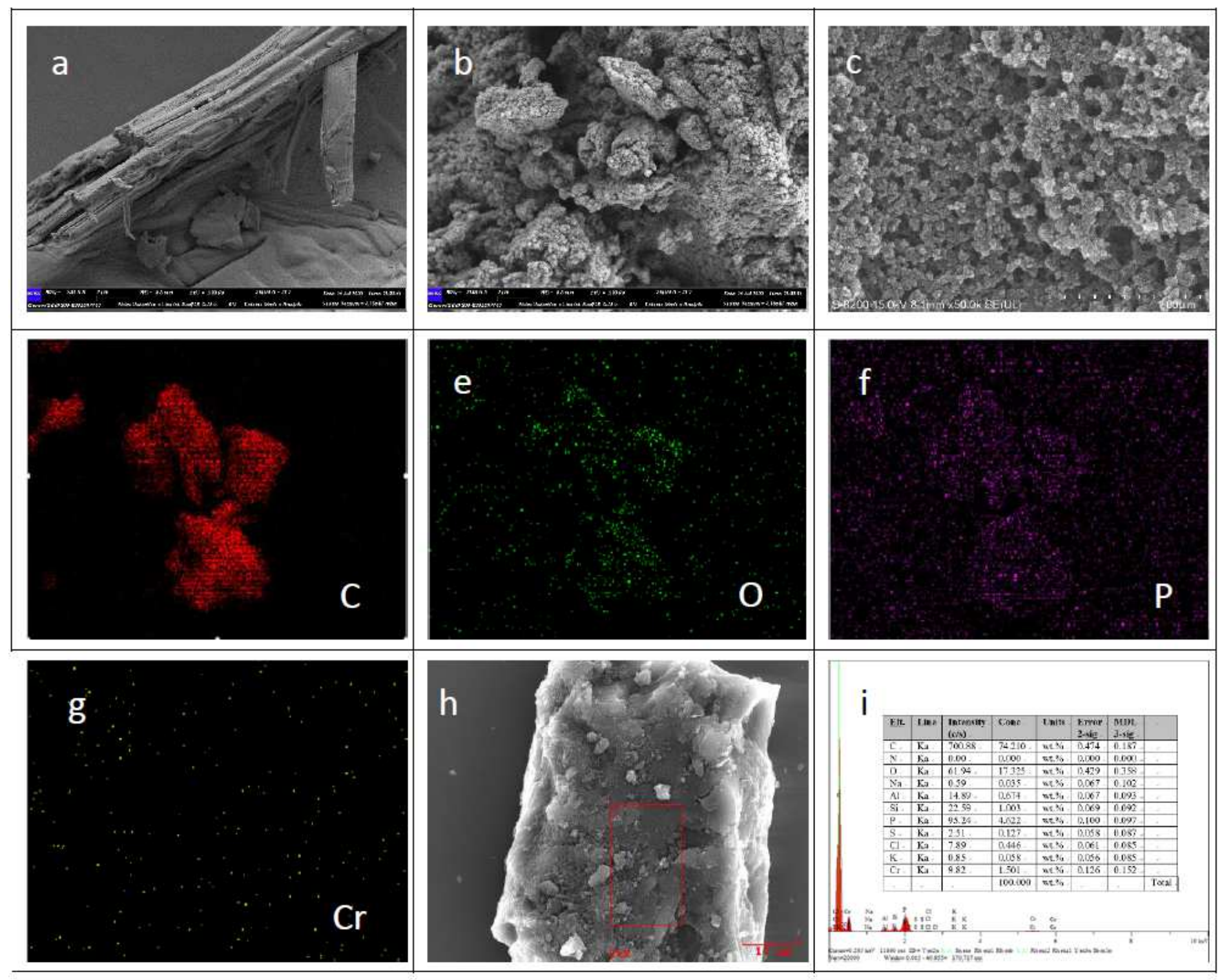

Figure 7

SEM images of Pennisetum giganteum (a); Zp-pgBC- $400^{\circ} \mathrm{C}$ before (b) and after (c) Cr adsorption; Elemental mapping of (d) $\mathrm{C},(\mathrm{e}) \mathrm{O},(\mathrm{f}) \mathrm{P},(\mathrm{g}) \mathrm{Cr}$; (h) EDS point scan analysis area and (j) the corresponding EDS patterns. 


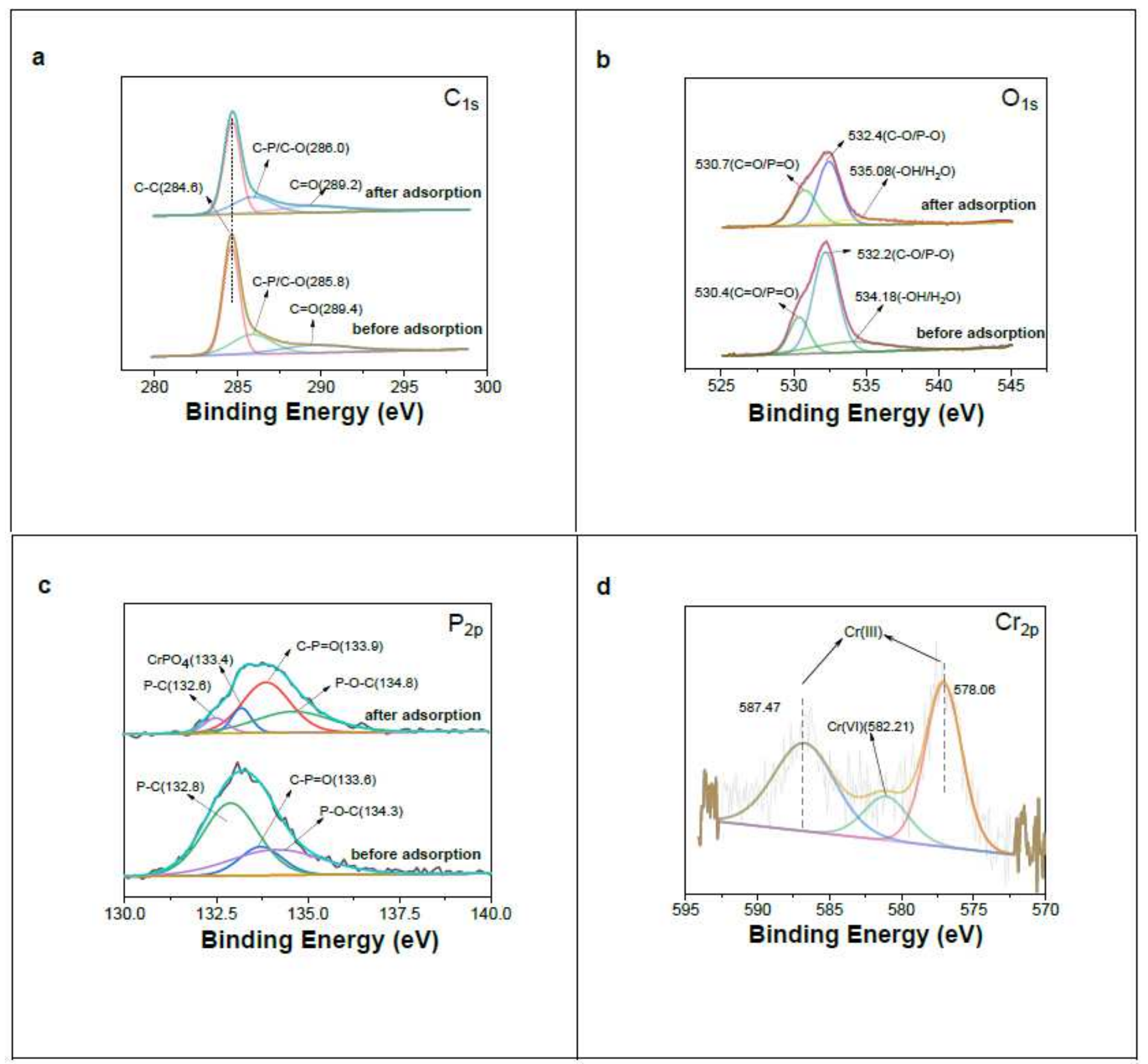

Figure 8

XPS spectrum of Zp-pgBC- $400^{\circ} \mathrm{C}$ before and after $\mathrm{Cr}(\mathrm{VI})$ adsorption. (a) $\mathrm{C} 1 \mathrm{~s}$, (b) 01s and (c) P2p and (d) Cr2p. 


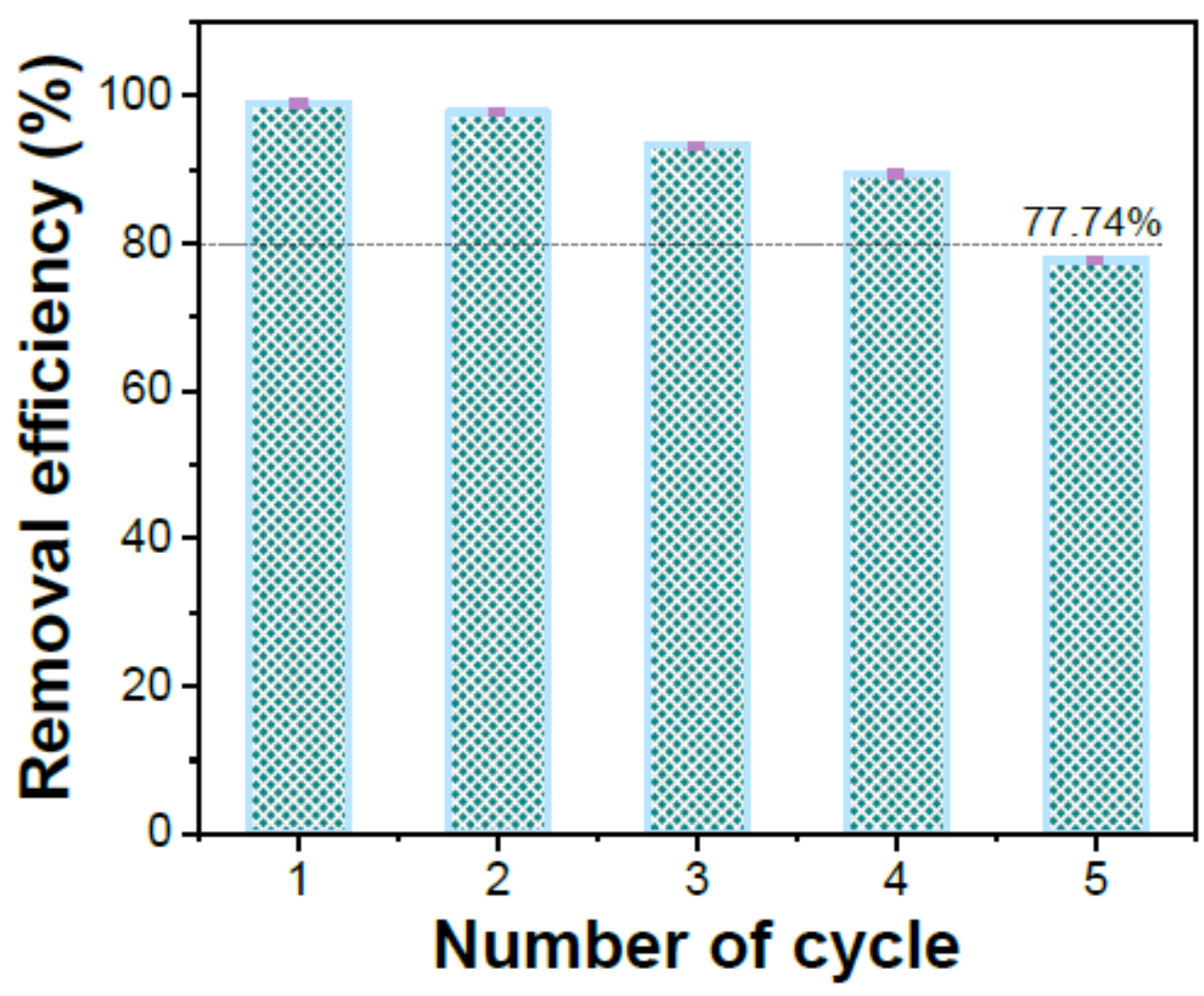

Figure 9

Cycle times of $\mathrm{Zp}-\mathrm{pgBC}-400^{\circ} \mathrm{C}$ on $\mathrm{Cr}(\mathrm{VI})$ removal efficiency

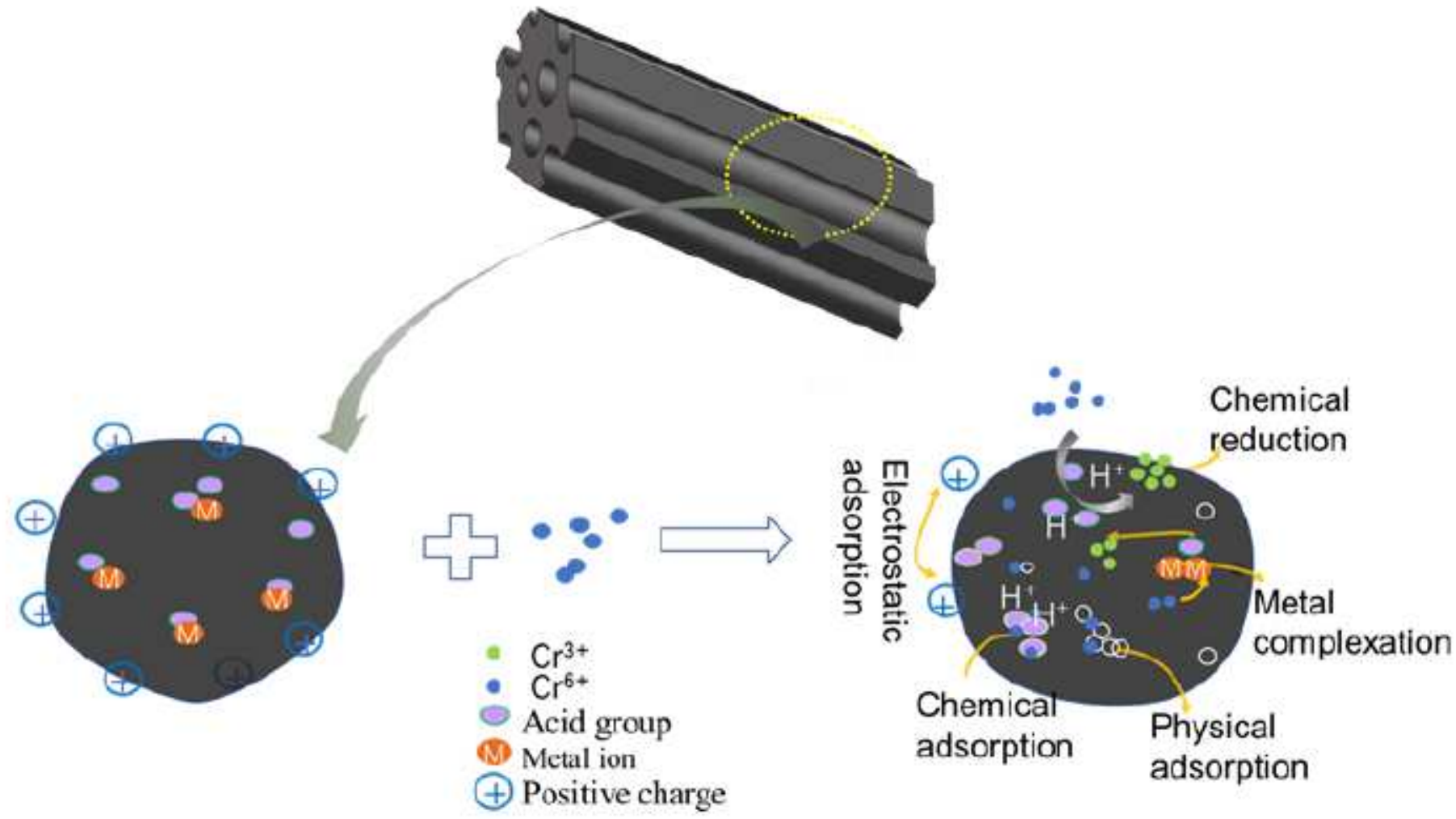


Figure 10

Schematic illustration of $\mathrm{Cr}(\mathrm{VI})$ removal mechanism

\section{Supplementary Files}

This is a list of supplementary files associated with this preprint. Click to download.

- GraphicalAbstract.png

- supportinformation.docx 